\title{
Evaluation of a Nurse-led Telephone Intervention with Symptomatic Heart Failure Patients
}

\author{
Samantha Stone \\ West Virginia University
}

Follow this and additional works at: https://researchrepository.wvu.edu/etd

\section{Recommended Citation}

Stone, Samantha, "Evaluation of a Nurse-led Telephone Intervention with Symptomatic Heart Failure Patients" (2012). Graduate Theses, Dissertations, and Problem Reports. 3606.

https://researchrepository.wvu.edu/etd/3606

This Dissertation is protected by copyright and/or related rights. It has been brought to you by the The Research Repository @ WVU with permission from the rights-holder(s). You are free to use this Dissertation in any way that is permitted by the copyright and related rights legislation that applies to your use. For other uses you must obtain permission from the rights-holder(s) directly, unless additional rights are indicated by a Creative Commons license in the record and/ or on the work itself. This Dissertation has been accepted for inclusion in WVU Graduate Theses, Dissertations, and Problem Reports collection by an authorized administrator of The Research Repository @ WVU.

For more information, please contact researchrepository@mail.wvu.edu. 
Evaluation of a Nurse-led Telephone Intervention with Symptomatic Heart Failure Patients

Samantha Stone, MSN, FNP-BC

Doctoral Research Project submitted to the School of Nursing at West Virginia University in partial fulfillment of the requirements for the degree of

\author{
Doctor \\ of \\ Nursing Practice
}

\begin{abstract}
Alvita Nathaniel, PhD., FNP-BC, Chair
Elaine Davis, EdD., RN

Ronald McCowan, M.D.

Department of Nursing
\end{abstract}

Morgantown, West Virginia

2012

Keywords: heart failure; nurse-led telephone intervention; quality of life; selfmanagement 


\begin{abstract}
Evaluation of a Nurse-led Telephone Intervention with Symptomatic Heart Failure Patients
\end{abstract}

Samantha Stone, MSN, FNP-BC

Heart failure (HF) is a chronic illness that affects approximately 550,000 Americans each year. By 2037, the prevalence is expected to double. Many symptomatic HF patients have difficulty managing their symptoms and are often readmitted within thirty to sixty days after hospital discharge. Research has shown that symptom management and quality of life can be improved in HF patients by utilizing a nurse-led telephone intervention. With improved symptom management patients not only experience a better quality of life, but, HF hospital admission and readmission rates can be reduced. The objectives of this capstone project were to 1) increase patient awareness about their illness, 2) improve symptom management, and 3) improve their quality of life by utilizing a nurse-led telephone intervention on a weekly basis for six weeks following a hospitalization for HF within the past six months. Following the intervention patients showed statistically significant improvement in symptom management and awareness of their illness. Although not statistically significant, they also had overall improved quality of life. 


\section{Table of Contents}

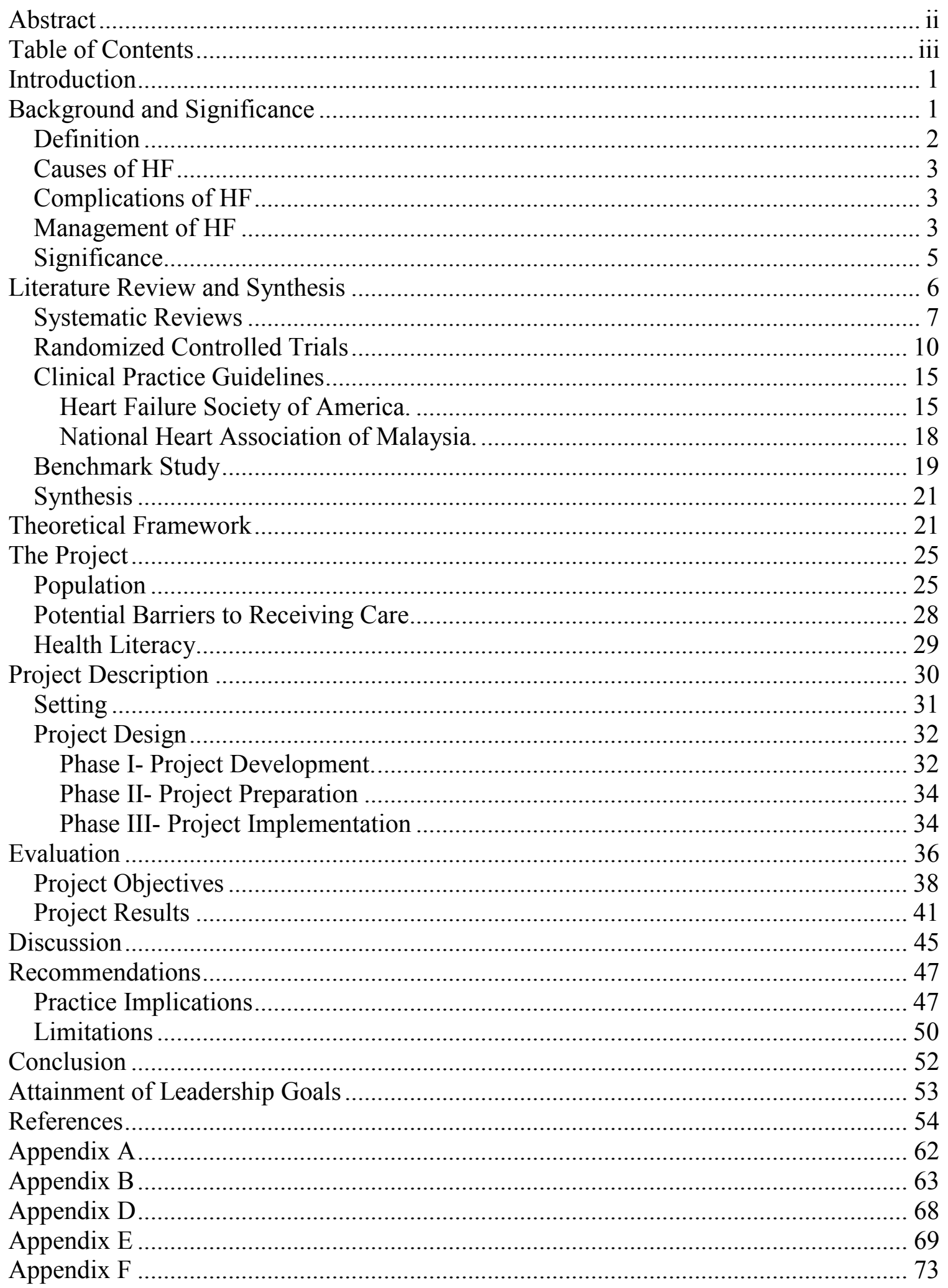




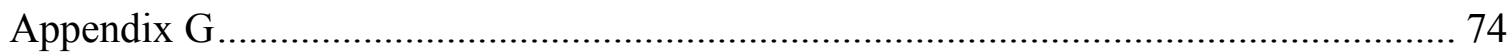

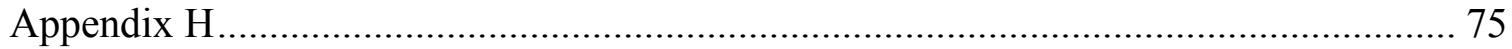

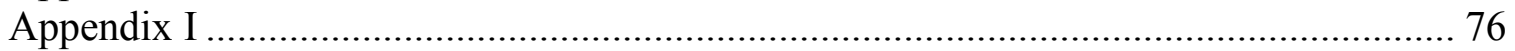

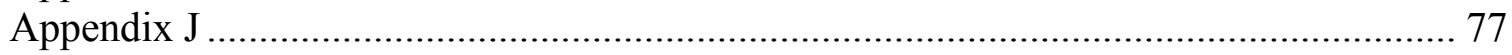




\section{Introduction}

This capstone project consisted of implementation of a practice change at a local cardiology office that utilized a telephone intervention with heart failure (HF) patients who have been hospitalized for symptomatic heart failure within the prior six months. The objectives of the project were to 1) increase patient awareness about their illness, 2) improve symptom management, and 3) improve their quality of life by utilizing a nurseled telephone intervention on a weekly basis for six weeks following a hospitalization for HF within the past six months. The problem that this practice change addresses is close to six million people in the United States are living with heart failure and without proper self-management and adherence to prescribed treatment regimens, quality of life is impaired and mortality is increased (American Heart Association, 2012). The goal of the telephone intervention is to provide education and support focused on improving patient's self-management of their HF and improving quality of life. This paper will discuss the following information about HF: background, definition, significance of the problem and literature that supports proceeding with the intervention. A description of the project along with the evaluation, results and implications for practice will be discussed.

\section{Background and Significance}

According to the American Heart Association Executive Summary on heart disease and strokes (2012), 5.7 million Americans are currently living with heart failure. The mortality rate is $56.8 \mathrm{~K}$ annually. The incidence of HF is higher in men than women and the prevalence is approximately 50\% higher in the Black population (AHA, 2012). Black males have the greatest prevalence at $4.5 \%$ but white females have the greatest 
mortality rate of $30.2 \mathrm{~K}$ annually. The increased incidence of kidney disease in the Black population could account for this greater prevalence (Bibbins-Domingo et al., 2006). The high incidence of diabetes and hypertension also contribute to the greater incidence of heart failure in the black population (Volkova, McClellan, Soucie, \& Schoolwerth, 2006).

\section{Definition}

Symptomatic heart failure results when patients who have the illness experience symptoms of difficulty breathing with exertion or when lying down, fatigue, edema of lower extremities, and weight gain. Some patients will also experience symptoms such as heart racing, dizziness, loss of appetite, or increased urinary frequency at night (Friedman and Quinn, 2008). The symptoms experienced by patients often vary in severity and the longer they go unreported to providers, the greater the risk of complications resulting in hospitalization. Currently, the average length of stay for heart failure patients is 5.2 days (Centers for Disease Control [CDC], 2009).

The New York Heart Association (NYHA) developed a functional classification system for categorizing the patient's level of severity of their heart failure based on reported symptoms as they relate to daily activities and quality of life. Class I is considered mild with patient's having "no limitation of physical activity." Class II is also considered mild but these patient's have a reported "slight limitation of physical activity." The moderate severity of symptoms is Class III and is classified when patient's have "marked limitation of physical activity." When a patient has severe symptoms and are "unable to carry out any physical activity without discomfort," they are in functional Class IV of the NYHA's functional class (Heart Failure Society of America [HFSA], 2012). 


\section{Causes of HF}

There is no definitive cause of HF. Heart failure results when the heart loses its ability to pump blood/oxygen appropriately throughout the body. However, the most common causes of HF are hypertension, diabetes, and coronary artery disease. There are also many other factors that contribute to HF which include: congenital defects, valvular incompetence, drug or alcohol abuse, chemotherapy treatment, kidney failure, uncontrolled cardiac arrhythmias, and myocardial infarction (National Heart Lung and Blood Institute [NHLBI], 2010).

\section{Complications of HF}

Depending on the cause and severity, people with HF will often experience many associated complications. The most severe complication of HF is death. Most patients' HF will result in death within five years of diagnoses. Heart failure also results in many symptoms such as, dyspnea, lower extremity edema, difficulty breathing at night, cough, decreased appetite, increased risk of cardiac arrhythmias and fatigue. Due to the significance of HF symptoms, multiple hospital admissions are associated with this chronic illness. Multiple hospital admission and mortality are increased when HF is complicated by depression (Sherwood et al, 2007). A recent study revealed that patients with HF and worsening depression over a one-year period were two times more likely to be hospitalized or suffer mortality than those whose depression did not change or actually improved (Sherwood et al, 2011).

\section{Management of $\mathbf{H F}$}

Unfortunately, HF can be difficult to manage. This is often due to lack of understanding about the illness and the importance of proper management by adhering to 
dietary restrictions, medication regimen, daily weights, and reporting symptoms prior to requiring hospitalization. Decreased quality of life results when HF is not managed properly often leading to depression which only complicates management.

The AHA Clinical Practice Guidelines (2009) recommend the following treatments for appropriate management of HF: diuretics (if fluid retention is evident), angiotensin converting enzyme inhibitor (ACEI) or angiotensin receptor blocker (ARB) and beta blocker (if not contraindicated), dietary sodium restriction (2-3 grams daily) and daily weight measurements. If there is dysynchrony of the ventricles, an implantable cardioverter defibrillator (ICD) or pacemaker that improves cardiac resynchronization may be implanted in HF patients. Patients with increased severity as evidenced by more severe symptoms, left ventricular dysfunction of $35 \%$ or less and an ischemic or dilated cardiomyopathy may benefit by having an ICD (AHA, 2009). Biventricular ICDs implanted to improve cardiac resynchronization not only can decrease the risk of sudden cardiac death but also allow for better cardiac output, therefore, improve HF symptoms, quality of life, and overall mortality rates (Ellenbogen, Kay \& Wilkoff, 2004).

In order to improve HF symptoms and quality of life, it is important that patients have a clear understanding of what has led to their diagnoses. It is also important that they understand the importance of lifestyle modifications that are necessary to decrease complications and minimize HF symptoms. These modifications include but are not limited to dietary changes, medication adherence, participating in cardiac rehabilitation programs (when prescribed by their physician), avoiding contributing factors such as alcohol, tobacco use, and medications that can exacerbate their illness (AHA, 2009). 
They should also be open to considering modern technology (such as ICDs and biventricular devices) when indicated.

\section{Significance}

Heart failure is a significant problem in the United States. Because of the high prevalence, it can be life-threatening, and patients often experience severe symptoms. Most patients diagnosed with HF will experience mortality within the first five years of diagnosis. Heart failure contributes approximately 60,000 United States deaths annually (AHA, 2012); however, it is most likely a contributing factor rather than the essential cause of death (Goldacre, Mant, Duncan, \& Griffith, 2005). Patients with HF are at an increased risk of sudden cardiac death due to a reduced ejection fraction (EF) and abnormal contractility of the heart muscle; both of which contribute to an increased risk for fatal arrhythmias (AHA, 2006). A decreased EF in patients with left ventricular systolic dysfunction is one of the strongest predictors of mortality (Bhatia et al., 2006). The Studies of Left Ventricular Dysfunction (SOLVD) is a landmark study that examined mortality rate in relationship to EF and concluded that as ventricular dysfunction decreased, mortality rate increased (Greenberg et al, 2005).

This project is significant because Appalachian patients with heart failure are at risk for high rates of mortality and morbidity due to difficulties in self management of their illness, including adhering to complicated medication schedules, required lifestyle changes, and lack of knowledge about the disease (Deskins et al., 2006). Studies have shown that nurse-led telephone interventions can be effective in reducing hospital admissions, mortality rates, length of hospital stay, patient knowledge, self-management, 
and adherence in HF patients (Battersby, 2005; see also Caldwell, 2005; Clark, 2007;

GEISCA, 2005; Gonseth, 2004; Jaarsma, 2008).

\section{Literature Review and Synthesis}

A rigorous search of literature dated January 1995 to March 2011 was conducted using multiple data bases (OVID, PubMed, CINAHL, Cochrane Library, National Guidelines Clearinghouse, and the Scottish Intercollegiate Guidelines Network [SIGN]) and focused on research articles that were written in English. From the most appropriate studies, snowballing was also used to obtain further studies. The search terms used for the obtaining appropriate studies included the following: heart failure interventions, heart failure telehealth, heart failure post discharge, heart failure readmission rates, telehealth, telehealth and readmission rates, discharge and readmission rates in heart failure, readmission risk for heart failure, phone support and heart failure, phone support and readmissions, heart failure and education and heart failure, education and interventions. The initial review focused on research articles that included at least one telephone intervention. After all articles were reviewed, it was necessary to further narrow the review, therefore, only articles that included a telephone intervention for heart failure patients were included. The final results for the literature review includes three systematic reviews, four randomized control trials (RCTs), one benchmark study, and two clinical practice guidelines. All systematic reviews and RCTs were evaluated using the SIGN (Scottish Intercollegiate Guideline Network, 2008) critical appraisal forms. There were two clinical practice guidelines that were evaluated for internal validity by use of the Appraisal of guidelines for research and evaluation (AGREE, 2001) instrument. 


\section{Systematic Reviews}

Three systematic reviews were critically appraised for evaluation of a nurse telephone intervention in chronic heart failure patients. A systematic review by Battersby, Holland, Harvey, Lenaghan \& Hay (2005), focused on a multidisciplinary approach to four types of outpatient support programs for heart failure patients. The purpose of this systematic review was to determine whether utilization of a multidisciplinary team that consists of a nurse, pharmacist, dietician, or social worker would decrease hospitalization and mortality rates in heart failure patients. There were 13 European trials, 13 United States trials, one Argentinean and three Australian for a total of 30 RCTs. There were a total of 1909 patients in all studies combined. The inclusion criteria in each study were similar and the mean age was between 56-86 years. The ratio of men to women in the combined studies was unclear. The severity of heart failure varied with patient ejection fractions ranging between $22-43 \%$. The interventions were divided into four subgroups which included the following: subgroup A included at least some home health visits, subgroup B utilized a form of telemonitoring either via videophone or reporting of physiological findings, subgroup $\mathrm{C}$ included a telephone intervention or mailing, however, there were no home visits, and subgroup D included interventions that were provided in an inpatient setting, clinic or physician office.

Twelve of the trials in this review utilized telephone interventions. Overall hospital admissions, heart failure admissions, and length of stay were decreased when a home-based intervention was utilized. Use of a telephone intervention revealed a decrease in heart failure admissions and mortality. However, telephone interventions did not decrease overall hospital admissions (2005). A strength of this review is that evidence 
from studies indicated heterogeneity among the telephone-based interventions with a $p$ value of $<0.001$ (2005). A weakness of this review is that there was no mention of costeffectiveness in any of the studies which may leave readers questioning feasibility of the interventions. The broad range of age and ejection fractions could also be considered a weakness because patients who are older and have lower ejection fractions typically have poorer outcomes.

In a systematic review by Clark, Inglis, McAlister, Cleland, and Stewart (2007) addressed the question of whether the use of remote monitoring (either by telephone or telemonitoring) without additional home or clinic visits would improve outcomes in heart failure patients. The search of 15 electronic databases, contacts with experts and authors as well as the use of snowballing identified 14 RCTs for a total of 4264 patients. The mean age of the study population ranged from 57-75 years. The inclusion criteria for the studies were similar and it is clearly noted that only interventions that were directed toward the patient were included in this review. Primary outcomes addressed mortality, all-cause hospitalizations, and admissions due to heart failure. Secondary outcomes evaluated quality of life, cost, and acceptability. All cause mortality was reduced in all 14 RCTs with the use of remote monitoring. However, telemonitoring proved to be more beneficial than telephone support only. There was no statistically significant evidence to support that either intervention decreased all cause hospital admissions. Only one study reported the benefits of remote monitoring in heart failure admissions as being statistically significant. However, it was unclear whether the intervention of telephone support or telemonitoring was of greater advantage to the patients. It should be noted that studies that evaluated the use of a telephone support concluded that this type of 
intervention was cost effective (2007). Strengths of the review demonstrated that remote monitoring may likely be a cost-effective intervention for patients with heart failure, and supports the need for further research. Weaknesses were the small number of RCTs included and that few studies evaluated the interventions beyond six months.

A third systematic review addressed the study question of whether or not disease management programs decrease hospital re-admission rates in patients with heart failure (Gonseth, Guallar-Castillon, Banegas, \& Rodriquez-Artalejo, 2004). The study quality was assessed using the Jadad scale (Jadad et al, 1996) for the RCTs. Nonrandomized control trials were assessed for quality by examining the degree of control for confounding factors. All studies had similar inclusion criteria and all studies in this review assessed disease management programs in heart failure patients. A total of 27 RCTs and 27 nonrandomized control trials were reviewed. Patients in the studies had a mean age of 70 years. The interventions focused on educational components of heart failure and patient support. Telephone intervention was noted in all but three of the studies. Although telephone interventions were part of the majority of the studies, it was unclear whether or not this approach provided any benefit (2004). The lack of clarity of the benefit resulting from a telephone intervention could certainly be considered a weakness. Another weakness was the lack of a clear explanation of the actual interventions in the disease management programs. However, this review did provide evidence that overall disease management programs do reduce heart failure readmissions, mortality, and all-cause hospital readmissions in elderly heart failure patients. The studies also concluded that these programs can also be cost effective (2004). 


\section{Randomized Controlled Trials}

The GESICA Investigators reported on the RCT called the "DIAL" trial (2005). The purpose of this RCT was to establish whether or not the use of telephone interventions in heart failure patients would decrease mortality or heart failure admissions in patients with chronic heart failure. The study consisted of 1518 participants (758 in usual care group and 760 in the intervention group) who were diagnosed with chronic, stable heart failure with a mean age of 65 years. The multicenter study took place in Argentina and the full study is currently only available in the Spanish language. The intervention used in this RCT was frequent follow-up calls offering education, counseling, and monitoring in addition to usual care. There were five main objectives of the interventions (medication and dietary compliance, heart failure symptoms, daily weights, and physical activity) and these were assessed with the use of pre-scripted questionnaires and consistent intervention procedures. Nurses were allowed to make adjustments in diuretic doses and recommend an additional medical follow-up or emergency care based on findings. The first four telephone interventions were scheduled and other calls were instituted based on study criteria as evidenced by information obtained during previous calls. Primary outcomes were all cause mortality and worsening heart failure hospitalizations. Secondary outcomes were quality of life, total mortality, all cause hospitalizations, and cardiovascular admissions (including worsening heart failure). Results of this study confirmed that a telephone intervention in patients with heart failure can be beneficial in reducing heart failure complications, as evidenced by a decrease of symptoms, cardiovascular admissions, and in enhanced quality of life. The control group was more likely to be admitted for worsening heart failure but mortality was comparable 
in both groups (2005). Strengths of this study are the design and that there was a decrease in the risk for bias due to the fact that the clinical events committee was blinded to the assignments. Additionally, the sample size was adequate; therefore, the study is feasible and effective.

Caldwell, Peters, and Dracup (2005) involved a pilot study in their RCT that examined whether or not a "simplified" education program and counseling intervention in heart failure patients could enhance knowledge, reported self-care behavior, and decrease disease severity. The participants were randomized into two groups. The intervention group received individualized education and counseling which focused on symptom management. They also received a follow-up telephone call within one month for additional support. Patients were advised to call their doctor with weight gain of three pounds in a day or five pounds in a week. Potential barriers were discussed and patients in the intervention group were given a weight diary and written instructions on what to do when there was worsening of symptoms. There were 36 study participants (16 in the control group and 20 in the intervention). The mean age of the patients was 71 years, the majority of the participants were men, and most had a preserved EF of $>45 \%$. Study findings confirmed that the intervention did increase patient knowledge after three months when compared to the control group $(p=0.1)$ which had no change at three months. Self-care behaviors were also reported higher in the intervention group $(p=0.3)$ and at three months the intervention group reported a significantly higher incidence of obtaining daily weights $(\mathrm{p}=0.002)$. When asked about reporting worsening symptoms to the physician, there was no noted difference between groups. As evidenced by a followup brain natrieutic peptide that was compared to baseline, the disease severity in the 
intervention group was lower but the difference was not statistically significant $(p=0.21)$ (2005). Weakness of this study is the homogeneous, small sample size, and the short duration of follow-up. The strength of this study is the design.

The objectives of the Cleland et al (2005) RCT study were to determine whether or not home telemonitoring when compared to a nurse telephone intervention or usual care improved outcomes in patients with HF who were at high risk for hospitalization or death. The sample size was 426 and the patients were randomized into three groups (usual care $n=85$, nurse telephone intervention $n=173$ and home telemonitoring $n=168$ ). Inclusion criteria for this RCT were a recent hospitalization for heart failure and an ejection fraction of less than $40 \%$. Exclusion criteria included patients under the age of 18 , unable to utilize home telemonitoring, or awaiting further cardiac interventions. All participants in the study received a written management plan that was individualized and focused on left ventricular (LV) dysfunction and medication management. The mean ejection fraction for patients in this study was $25 \%$. The treatment plan was sent to the patients' primary care physicians for those in the usual care group and a follow up was scheduled every four months at the research center. The patients in the telephone intervention group were given the same plan but also received a monthly phone call by the nurse. At the time of the call, the nurse evaluated the patient's symptoms and medication regimen. The nurse also advised the patient as needed and communicated the findings to the primary care provider. Patients randomly assigned to the home telemonitoring group also received the nurse telephone intervention along with usual care. In addition, the home telemonitoring group had the benefit of a home monitoring device that monitored weight, blood pressure, and electrocardiogram. Participants were 
instructed to submit measurements prior to breakfast and dinner, after they emptied their bladders, only wearing light clothing without shoes and prior to taking medications. Abnormal findings were evaluated by the research nurse who then charted the information and instituted any necessary interventions.

The primary end point for this study was to determine if length of hospital stay would differ between groups when hospitalized for heart failure. The study duration was limited to 240 days to ensure that the duration and mortality did not interfere with outcomes. However, there was a 450 day follow up done for comparison. Secondary end points of this study were all-cause mortality, symptoms, and optimization of medications. Hospitalizations were categorized by heart failure, other cardiovascular causes, or noncardiovascular admissions. Results of the study revealed that those in the home telemonitoring group when compared to the nurse telephone intervention had a decreased length of stay when admitted for heart failure. However, there were no differences when compared at 450 days. Patients in the usual care group had a higher incidence of mortality and increased loss of days due to death or hospitalization than those in the nurse telephone intervention or home telemontioring group (2005). Ninety-six percent of the patients in the home telemonitoring group reported "good or very good" satisfaction with the intervention. The study did not reveal how the satisfaction data was obtained. There was also no mention of patient satisfaction in the other groups. Strengths of this study include the sample size, severity of illness (as evidenced by a mean EF of $25 \%$ ), and the high patient satisfaction rate in the home telemonitoring group. A weakness may be that there was potential for bias in patients in the home telemonitoring group to have shorter 
lengths of stay because the physician might be more likely to discharge a patient sooner knowing they have use of this technology at home.

The last RCT reviewed was a multicenter trial that enrolled 1023 participants following a heart failure hospitalization (Jaarsma et al., 2008). The mean age of the participants was 71 years. Patients were randomized into either the control group or one of the two intervention groups. The control group was followed by a cardiologist. The intervention groups received additional follow-up with a heart failure nurse specialist. The intervention by the heart failure nurse specialist was either basic or intense depending on which intervention group the patient was assigned. In addition to the follow up with the cardiologist, the basic intervention group was also scheduled for a visit with the HF nurse in the outpatient clinic. During the follow up with the HF nurse, behavioral strategies in order to increase adherence were discussed. Participants were also instructed to notify the HF nurse if there were changes in their conditions. Those who were in the intense intervention group received monthly contact with the HF nurse, weekly phone contact during the first month after discharge, and a home visit by the HF nurse. The intervention for all groups included a follow up with the cardiologist two months after discharge and then every six months. All participants were followed for 18 months. The groups receiving the intervention were visited prior to discharge by the HF nurse specialist and outpatient follow ups were scheduled in the outpatient clinic. The focus of the interventions was education and support. The goal was to improve compliance to treatment and to initiate behavioral strategies. Patients also received interventions by a multidisciplinary team which included a physiotherapist, dietician, and social worker. The heart failure nurse was trained to enhance self-efficacy with the use of educational 
materials including patient diaries, HF brochures, and written instructions on dietary restrictions. The primary end points of this study were combined HF hospitalizations or all cause mortality, and days lost due to death or hospitalization. Secondary end points included all-cause mortality, HF admissions, and the total of all-cause hospitalizations. This study concluded that there is no benefit to adding a nurse-led intervention in addition to cardiology follow up (2008). However, both intervention groups did have a $15 \%$ decrease in all-cause mortality rate and a slightly decreased length of stay (2008). Strengths of this study are the large sample size and a multi-center design which increases its generalizability to the population. There is no clear weakness in this large RCT.

\section{Clinical Practice Guidelines}

Heart Failure Society of America. The first clinical practice guideline, herein referred to as guideline, was developed by the Heart Failure Society of America (HFSA, 2010) but involved multiple disciplines including nurses, pharmacists, and physicians. The objectives of this guideline were prevention, evaluation, disease management (including pharmacologic and device therapy), genetic evaluation, and end-of-life management of HF patients. RCTs, cohort and case-control studies along with expert opinion were utilized to support the recommendations. Likewise, each recommendation was distinguished by a grade of A, B or C based on strength of evidence. RCTs were graded with an A (most valid), cohort or case-controlled studies were graded as a B and the letter $\mathrm{C}$ was used for expert opinion. A classification system was also utilized to note the strength of the recommendation. When a recommendation was noted to be part of routine care it was classified as "is recommended", "should be considered" indicates that 
the majority of patients should receive the particular intervention with discretion, "may be considered" is used when an individualized therapy is needed and "is not recommended" specifies a therapeutic intervention should not be used. There were no patient views sought. The development of this guideline occurred after all available heart failure literature was reviewed and evaluated for strengths and weaknesses. The HFSA guideline takes into consideration side effects, health benefits, and risks. Multiple recommendations for heart failure patients vary based on underlying disease process, risk factors, clinical presentation, severity of LV dysfunction, and patients' symptoms. According to this guideline, patients who have known HF should be closely evaluated for clinical severity, cardiac function and structure, underlying causes, potential risks, signs of worsening HF, co-morbidities, and barriers that may influence adherence. According to this guideline, there are seven factors that can be modified in order to decrease hospital readmission rates which include the following: inadequate education and counseling; poor communication and coordination of care; inadequate discharge planning; failure to organize proper follow-up care; failure to emphasize non-pharamacological aspects of care such as symptom monitoring and recommendations when symptoms occur, dietary and activity monitoring; failure to address issues that can be barriers to care; and failure of providers to utilize evidenced-based care and adhere to published guidelines.

Also included in the HFSA guidelines are "Elements of Patient Education with Associated Skills and Target Behaviors" (2010). Heart failure patients need to understand what the diagnosis of HF means and have to ability to link their illness to associated symptoms, treatment and cause. They have to be able to recognize worsening symptoms and have a solid plan as to how to respond. Patients who have HF are on multiple 
medications which is known as poly-pharmacy. Due to poly-pharmacy, understanding why they are taking particular medications and how to use them appropriately is essential for HF patients. In addition, they need to be able to modify their risks for progression of their illness. Education about dietary restrictions and levels of activity that are recommended for these patients with HF needs to be provided. As with any illness, HF patients need to have a clear understanding of the importance of adhering to treatment recommendations and be able to identify behavioral strategies that promote wellness.

Heart failure patients often don't know how to self-manage their illness. This often results in nonadherance. Therefore, as clinicians treating HF patients, there is a responsibility to encourage skill building that targets critical behaviors. The HFSA guidelines recommend the following: 1) discuss basic HF information such as cause and how symptoms relate to health status; 2) identify symptoms that are specific to HF, such as increased fatigue or shortness of breath with normal activity or at rest, orthopnea and edema; 3) daily weight measurements and how to respond to the findings; 4) have an action plan denoting when the provider should be notified and when changes should be made; 5) stress the importance of each medication and the role it plays in their treatment; 6) modify risks factors for worsening HF, such as smoking, alcohol abuse, uncontrolled hypertension and diabetes; 7) maintain weight recommendations; 8) understand and comply with sodium restrictions; 9) demonstrate how to properly assess foods for sodium by reading food labels and sorting foods into high and low-sodium groups; 10) comply with activity recommendations, and 11) devise a medication system that promotes adherence and a plan for refills. 
National Heart Association of Malaysia. The National Heart Association of Malaysia also focused on heart failure and was developed by the National Heart Association of Malaysia, Academy of Medicine and Ministry of Health (2007). This guideline was chosen because its objectives include: heart failure prevention, reducing morbidity, improving quality of life, and improving survival. The clinical questions covered by the guideline focus on diagnosis, prevention for high risk individuals, and effective treatment of acute and chronic heart failure based on current evidence. The Malaysia guideline also examines special groups such as: patients who are asymptomatic and have impaired LV function, patients with diastolic dysfunction, pregnant patients, and children with HF. However, the target group for this guideline includes all healthcare providers treating patients with HF. The target population is any person being treated for HF. The guidelines were developed by cardiologists, general physicians from both the private and government sectors, and public universities. It should be noted that there were no nurses or pharmacists on the panel. Patient views were not sought.

Evidence to support the Malaysia guideline was obtained from a systematic review of the heart failure literature and international guidelines on heart failure were also studied. The literature was graded and adapted from the American Heart Association (AHA) and European Society of Cardiology. The levels of evidence include: data obtained from multiple RCTs or meta-analyses (A), data taken from single RCT or large non-randomized studies (B) and expert opinions, case studies or standard of care (C). Recommendations were graded as follows: when there is evidence or general agreement that a specific treatment is "beneficial, useful and/or effective" (I), when there is conflicting evidence or difference in opinion of specific treatments (II), when evidence 
and opinion favor the treatment (II-a), when treatment is less established by evidence or opinion (II-b), when there is evidence or general consensus that the treatment is not beneficial and possibly could be harmful (III). Key recommendations of these guidelines for all patients include: use of ace inhibitor, angio-retensin blocker in those who can not tolerate an ace inhibitor, and beta-blockers. Additional treatments that may be indicated for select patients include: diuretics, antiarrhythmics, implantable cardioverter defibrillator or cardiac resynchronization therapy. The guideline was reviewed by a panel of experts that externally evaluated the publication. The document is up for review after three years or sooner as new clinical evidence becomes available (2007).

\section{Benchmark Study}

There is a benchmark study that was completed in 165 outpatient cardiology practices throughout the United States. There were 65 practice sites in the south, 54 in the northeast, 26 in the central region, and 20 in the west. There were 13 university practices, 36 non-university but teaching practices, and 108 non-university/non-teaching practices (Fonarow et al, 2010). The goal of the study was to improve the use of evidence based heart failure therapies in the outpatient setting and is acronymed IMPROVE HF study (Fonarow et al, 2007). In order to achieve the study goal, participating practices were provided with educational workshops, guideline-based treatment algorithms, and thorough HF management tools. The design is a prospective cohort study in which the data was collected retrospectively from patients' medical records. There were three separate cohorts. Cohort A medical records were reviewed longitudinally over 24 months (once at baseline and post intervention at 12 and 24 months). Cohorts $\mathrm{B}$ and $\mathrm{C}$ consisted of different patients in which a single time point 
review of medical records was completed. Cohort B medical records were reviewed postintervention at 6 months and cohort $\mathrm{C}$ at 18 months. The populations studied included those diagnosed with HF or prior myocardial infarction and left ventricular dysfunction being treated in an outpatient setting. The purpose was to evaluate practice improvement strategies. Based on information gathered via chart audits, performance feedback reports were provided to healthcare providers and physicians.

The benchmark quality reports were designed to assist practices to improve evidence-based HF treatments. Improvement was evaluated by means of the seven performance measures that were predetermined after review of the American College of Cardiology and American Heart Association clinical practice guidelines. The seven performance measures that were used for the study were based on patient eligibility and, if not contraindicated, included the following: 1) use of an ACEI (or ARB); 2) use of a beta blocker; 3 ) use of an aldosterone receptor antagonist; 4) use of anticoagulation therapy for patients with atrial fibrillation; 5) use of an implantable cardioverter defibrillator; 6) use of a cardiac resynchronization therapy, and 7) documentation that HF education has been provided. The primary goal of this study was to demonstrate a greater than $20 \%$ improvement in at least two of seven performance measures over a 24 month period. Secondary goals were to provide additional information in regard to practice change and treatment patterns (2007).

Primary findings of the IMPROVE HF study revealed that there was a statistically significant improvement in six of the seven performance measures at 12 and 24 months. In the cohorts $\mathrm{B}$ and $\mathrm{C}$ that were reviewed at a single time point ( 6 or 18 months); there was also an improvement in six of the seven performance measures (2010). 


\section{Synthesis}

Although results did vary among studies, there were enough positive findings to support the capstone project utilizing a nurse-led telephone intervention. One systematic review (Battersby et al., 2005) supported evidence that telephone nurse-led interventions can assist with the reduction of heart failure admissions and decrease mortality. Another review (Clark et al., 2007) did not confirm the reduction in hospitalizations but found telephone support to be cost effective. Cost effectiveness was also found in the Gonseth et al. (2004) study. Studies by Battersby et al. (2005) and Gonseth et al. (2004) both indicated that disease management programs can prove to be beneficial in reducing heart failure admissions, decreasing mortality and length of hospital stay. The Caldwell (2005), COACH (Jaarsma et al., 2008) and GEISCA studies (2005) revealed that a nurse-led telephone intervention can aid in decreasing HF admissions, overall cardiovascular admissions, mortality, and length of stay, as well as increase patient knowledge, self-care behaviors, and adherence to daily weight measurements.

Based upon the evidence presented above, this project will focus on developing a nurse-led telephone intervention for HF patients, and evaluating its impact on patients' adherence to their HF treatment (i.e. medication regimen, dietary restrictions, exercise plan and daily weight measurements), improving quality of life, and ultimately decreasing hospital readmission rates for symptomatic HF patients.

\section{Theoretical Framework}

The Health Belief Model (HBM) is a psychological theory that was developed by psychologists in the late 1950s (Rosenstock, Stretcher, \& Becker, 1988). The purpose of 
this theory is to describe motivators that influence health behaviors. The authors did determine that personal beliefs influence health behaviors.

While the Health Belief Model theory was originally defined by four concepts, it now is expanded to the following six concepts 1) perceived susceptibility 2) perceived severity 3) perceived benefits 4) perceived barriers 5) cues to action and 6) self-efficacy (Rimer \& Glanz, 2005). The theory can help predict how patients will behave based on their personal beliefs. It can easily be applied to situations that relate to patient adherence and health promotion actions which is a common problem among HF patients (van der Wal, Jaarsma, Moser, Veeger, Gilst, \& Veldhuisen, 2005).

Perceived susceptibility is one's personal thought of what they feel is their risk to a particular illness (Rimer \& Glanz, 2005). Lack of susceptibility does not imply an individual does not have concern for their health. There are many factors that can influence a person's perception of susceptibility such as: lack of knowledge about the illness and prevention, cultural beliefs, and or belief that it could not happen to them (Van der Pligt, 1996). People who feel that they are at risk for heart failure may be more likely to participate in activities that can decrease their risk or improve outcomes. It is well documented that those who have high blood pressure, underlying heart disease, and or kidney disease are at a high risk for developing heart failure at some point in their life. However, if the patients are not aware that risks are present, they are less likely to perceive susceptibility or do anything to prevent an increase in severity.

Prevention plays an important role in decreased severity when treating HF patients. Perceived severity is a belief about the seriousness of the condition and its consequences (Rimer \& Glanz, 2005). If HF patients have a true understanding about the 
seriousness of their illness and the consequences associated with it, the Health Belief Model suggests that they may be more likely to adhere to treatment regimens (van der Pligt, 1996). A meta-analysis of health beliefs, disease severity, and patient adherence concluded there is a statistically significant relationship among perceived severity and patient adherence. The more patient's understood the severity of their disease, the more likely they were to adhere to recommended treatments because they perceived them as benefits (DiMatteo, Haskard, \& Williams, 2007).

A perceived benefit is the perception that recommended treatments may reduce the seriousness or risk of an illness (Rimer \& Glanz, 2005). Once an individual accepts the susceptibility and possible severity of a particular illness, they are more likely to engage in health protective behaviors (van der Pligt, 1996). Two studies (Bennett et al, 2005; Bennett, Hays, Embree, \& Arnold, 2000) focused on the clinical problem of HF using the HBM as the theoretical framework. Both studies concluded that patients lacked knowledge about the benefits of medications and dietary restrictions used to treat HF, especially diuretics, and decreased sodium intake. However, when the benefits were evident following a tailored intervention, medication and dietary compliance improved. Although an individual may have a clear understanding of the benefit of a recommended treatment, they may still see it as costly, inconvenient, or having negative consequences (Becker, 1974).

Perceived barriers are about the material and psychological costs of the recommended behaviors and often result in negative consequences (Rimer \& Glanz, 2005). Negative consequences that result from a particular action are known as perceived barriers and can often lead to non-adherence (Bennett, Lane, Welch, Perkins, \& Brater, 
2005). Because perceived barriers are so closely related to non-adherence and perceived severity, it is important for health care providers to understand which ones are common among HF patients. Non-adherence to dietary restrictions and HF medications were common in the Bennett et al (2005) study. Patients were less likely to adhere to dietary restrictions because of the increased cost of buying "low-sodium" brands and the lack of flavor of low-sodium foods. Dietary restrictions can also limit patients' choices when they go out to restaurants (Bennett et al, $2000 \& 2005$ ). Additional barriers were related to medications used in treating HF patients such as diuretics. These can lead to unpleasant side effects such as increased urinary frequency as well as incontinence in some patients. When unpleasant side effects occur, patients are less likely to be adherent in taking their diuretics. Heart failure patients are instructed to weigh themselves daily. However, if one can not afford a scale for daily weights, this would be considered a barrier. When treating HF patients it is important to be aware of and assist the patient in ways to overcome potential barriers. Overcoming potential barriers can lead to cues to action.

Cues to action are factors associated with the willingness to participate in the recommended treatments (Rimer \& Glanz, 2005). According to Rosenstock (1974), cues to action can be either internal or external triggers that lead a person to participate in recommended health action. Triggers vary among individuals and are often related to perceived susceptibility and or severity. An example of an internal trigger in a HF patient may be that the patient doesn't want to weigh himself everyday because of his poor selfbody image. An external trigger can be anything that motivates the patient such as repetitive information given during office visits or knowledge gained from someone who 
has the same illness. However, although patients have been given the "cues to action" they must believe they can do it.

Self-efficacy is the assurance that recommended treatment and or behaviors can be successfully implemented (Rosenstock, Stretcher, \& Becker, 1988). One must believe that they are competent and have the confidence to believe they can overcome anticipated barriers and succeed. Previous studies have revealed when interventions were tailored to meet individual needs based on one's beliefs, the results were more favorable (Bennet et al, $2000 \& 2005)$.

The Health Belief Model provides a framework for better understanding psychosocial factors that influence adherence. When a health-care provider is aware of influencing behaviors, these behaviors can be addressed and treatment and education can be tailored to individual needs. Providing patients with honest and straightforward information about their illness can give patients the ability to take action to improve outcomes (Sethares \& Elliott, 2004).

\section{The Project}

\section{Population}

The target population for this capstone project was adult patients with a diagnosis of symptomatic heart failure who were being managed by a cardiology group in southern West Virginia. The patient population was limited to adults 65 years of age and older who have had a hospital admission for symptomatic heart failure within six months prior to the implementation of the project and were being managed by this cardiology group. Their heart failure diagnosis could have been new or the hospitalization could have been a result of an exacerbation of their HF. 
As of 2010, the population for Kanawha county, WV was 193,063 with $16.7 \%$ of the population 65 years of age or older, which is higher than the state average of $16 \%$ (US Census, 2010). According to the 2010 United States census, only $2.1 \%$ of this county's population speaks a language other than English in their home (U.S. Census, 2010). Approximately $86 \%$ of the county residents 25 years of age or older have a high school degree and $23.4 \%$ have a bachelor's degree or higher. In comparison, this is higher than the state average of $81.9 \%$ and $17.3 \%$, respectively (US Census, 2010). According to the most recent census measuring the percent of disability, in the population over the age of five, 22\% are disabled (U.S. Census, 2000). However, it is unknown what percentage of the population are disabled as a result of HF or other chronic illnesses.

The majority of the population in the target area is of the Appalachian culture. In order to successfully treat and motivate people of the Appalachian region, one has to have a clear understanding of their background and culture. The Appalachian region expands over 13 states and includes 406 counties (Halverson, Barnett and Casper, 2002). Appalachians are known to be very independent, family-oriented, and value their relationship with God. They are also known for their kindness and willingness to help others. However, they are cautious when it comes to strangers and are reluctant to change (Deskins et al., 2006). According to the Appalachian Regional Ministry (2011), there are four diverse groups in Appalachia. The first groups consist of those who are descendants of original settlers of the region. They are often land owners, politicians, and local business people. There is a sense of self-reliance, independence, strong work ethics, stability, and sound family bonds. Blue collar workers such as coal miners, loggers, or 
factory workers make up the second type of group. There is minimal education, limited skills, poverty, large families, and scant vocations within this group. The third noted groups are professionals who were relocated to Appalachia due to their profession. People in this group are often viewed as outsiders and are welcomed or accepted with caution by Appalachians. Those who have left Appalachia but since have returned to the mountains to care for a family member or some other reason, make up the fourth group and often find it difficult to readjust to lifestyle that they had once known (Appalachian Regional Ministry, 2011).

Appalachian people are often thought of as living in rural impoverished areas. Although West Virginia is the only state in which the entire state is considered rural Appalachian, many of the residents of Kanawha County live in more urban areas and are licensed professionals. Some of the target population were "born and raised" in the state, a common trait of the Appalachian people. However, there are also many newcomers. The majority of the people in Kanawha County (89.1\%) are White. In this county, the Black or African American population is $50 \%$ higher than the state average $(7.3 \%$ compared to 3.4\%) (U.S. Census, 2010). Medicare and Medicaid are the major insurance payers for this population (Joshi, D’Souza, \& Madhavan, 2007). However, there are many people who are uninsured and underinsured. The average household income for the area is $\$ 42,669$, which is higher than the state's average of $\$ 38,380$ (U.S. Census, 2010). There are three hospitals in this county, all of which currently provide cardiac services. However, there is only one hospital that provides a heart failure clinic.

Patients with HF are typically older, serve as their own caregivers, manage complicated medical treatment, maintain close contact with the health care provider, and 
are asked to make changes in their lifestyles (Bennett et al, 2005). These changes may be more difficult for many patients in West Virginia due to lack of understanding about their illness and importance of self-management. The overall population of the state is decreasing because younger residents are leaving older parents behind in pursuit of jobs that are out of state. As a result, patients with chronic illnesses are being left behind with limited support from family members. Decreased support can also contribute to feelings of hopelessness leading to depression which complicates HF management.

\section{Potential Barriers to Receiving Care}

As mentioned previously, Appalachian people are known for their reluctance to change. Deskins et al. (2006), found that adults in West Virginia had "attitudinal barriers" to health care. The study revealed that people held concerns about the outcome of tests, fear of needles, resistance to change, lack of knowledge about heart disease, fatalism, and denial. The authors concluded that these findings are common characteristics of the rural Appalachian population with a low socioeconomic status and can serve as a barrier in the self-management of chronic illnesses such as HF (2006).

Many research studies about health care within the Appalachian population have concluded that access to health-care services is a widespread barrier (Behringer et al., 2007, Huttlinger, Ayers and Lawson, 2004 and Smith and Tessaro, 2005). While transportation can be a barrier, many of the people in this county have access to public transportation via county bus services. Although there is no mass transient system such as a subway system, buses provide accessibility for residents within the city and some adjacent rural communities (American Public Transportation Association, 2009). Many people in the community have cars that allow them access to health care. If they do not 
own a car, they will usually rely on a family member, neighbor, or transport service to get them to doctors' appointments. The county Department of Health and Human Resources office offers assistance for transportation reimbursement to allow better access to health care. Forms are taken to the physician's office by the patient, signed by a staff member, and submitted to the Department of Health and Human Resources for reimbursement. However, this process itself can be a potential barrier if its existence is limited and submission is cumbersome.

\section{Health Literacy}

The Institute of Medicine (IOM) defines health literacy as the "degree to which individuals obtain, process, and understand basic health information and services to make appropriate health care decisions"(IOM, 2004). A study of 19,000 adults (age 16 and older) done by the Institute of Education Sciences in 2003 revealed that only $12 \%$ of the US population had proficient health literacy (National Center for Education Statistics [NCES], 2006). Fifty-three percent had health literacy that was measured to be intermediate, $22 \%$ had basic health literacy and $14 \%$ were considered to be below basic in health literacy. Health tasks that required finding pieces of information that were straightforward and in short simple texts or documents were considered below basic. Basic tasks essentially required locating more complex information in texts or documents that were of greater lengths. A below basic task may be something such as finding a time or date on an appointment slip as compared to a basic task of finding specific health information in a pamphlet. Tasks that were consider intermediate required interpretation or application of information that was inside more complex health documents, graphs, or tables. Health tasks that were considered proficient required participants to draw abstract 
conclusions compare or contrast many pieces of information inside complex texts, or to apply abstract or difficult information from texts or documents.

Health literacy is also an ongoing barrier to care because it inhibits self-care which is important in the heart failure population. The problem is so significant that the Institute of Medicine (IOM) has made health literacy a focus of improving health care (Nielsen-Bohlman et al, 2004). According to researchers at Northwestern University's Feinberg School of Medicine (Chicago), low health literacy, which is equivalent to a fourth grade reading level (Baker et al., 1996), is not only a risk factor for poorer health, but, also associated with an increase in mortality. The increased risk of death was also found to be worse in the elderly population and in particularly, those suffering from cardiovascular disease. The same study revealed that out of 380 cardiovascular deaths, $7.9 \%$ had adequate health literacy, $16.7 \%$ had marginal health literacy and $19.3 \%$ were identified as inadequate in health literacy (Baker et al, 2007).

Although Appalachians are known for taking pride in providing and caring for themselves, without the understanding of the illness and treatment recommendations outcomes are more likely to be poor. The majority of participants in a study by Coyne, Demian-Popescu and Friend (2006), stated that people living in the regional part of southern West Virginia have low levels of medical knowledge and because of this, they seldom discuss health concerns outside of the family. However, it was difficult to find any literature that actually assessed health literacy levels in the Appalachian population.

\section{Project Description}

Since the rate of heart failure is expected to increase significantly over the next few years, it is important that health care providers have interventions developed to 
improve outcomes and decrease hospital readmission rates. There have been multiple studies that have evaluated interventions that address the heart failure population. Many studies evaluated a nurse-led telephone intervention. Although the outcomes varied with each evaluation, the project coordinator identified enough positive support of a telephone intervention to further evaluate it in the targeted population. According to participants' responses (Coyne et al, 2006), Appalachian people are lacking in medical knowledge. Therefore, it was anticipated that this project could enhance their knowledge about their HF. The capstone project was to implement a nurse-led telephone intervention for symptomatic HF patients who have had a hospital admission for HF within six months prior to implementation. As mentioned previously, the goal of the telephone intervention is to provide education and support that focuses on improving patient self-management of their HF and improving quality of life in patients being treated at a local cardiology office.

\section{Setting}

The setting for this capstone project was a local cardiology practice (WV Heart and Vascular Institute) established in 2006 by three board certified cardiologists. Their practice goal is to focus on heart failure patients and establish a large heart failure clinic in the area. The four current cardiologists serve 18,000 patients. One-third of their patients have a diagnosis of heart failure. Forty percent of the patient population in the practice are 65 years of age or older and have Medicare as their primary payer source. Medicaid is the payer source for ten percent of their patients, seven percent are private pay and the remaining patient population has third-party payers. There is no data available on the patients' gender, race or ethnicity. The office receives referrals from 
physicians in the county in which it resides and many surrounding counties in rural West Virginia.

WV Heart and Vascular Institute treat their heart failure patients as per Clinical Practice Guidelines (CPGs) recommendations. Regardless of participation, heart failure patients continued to be monitored and treated according to the institution's policy and procedures. Those patients who participated in the capstone project received care according to current practices and received an additional weekly telephone intervention for six weeks. All four of the board certified cardiologists in the practice and their staff supported the project (see letter of support in Appendix D) and collaborated in its implementation.

\section{Project Design}

Phase I- Project Development. In phase one the project coordinator reviewed literature to support of the project, identified the project setting and key stakeholders. Buy in was obtained from the stakeholders and a budget plan was created (appendix A) and used to assess feasibility of the project. The project coordinator also established a committee of three professionals who evaluated the project prior to implementation. The committee members also offered support and guidance to the project coordinator throughout the process.

The project coordinator also identified two appropriate tools to help guide the patient during the intervention. Both tools are recommended by the HFSA for educational use with HF patients and are of a fourth grade reading level. The Action Plan (Appendix F) is a tool that is designed to assist patients with what action to take when they do their daily assessment of HF symptoms. It has a stop light approach to make the process easy 
to follow. If the participant in this project has symptoms that are in the green zone, their symptoms are considered to be well controlled and do not require any further action. If symptoms are in the yellow zone, they may require medication changes and are encouraged to call their health care provider for specific instructions. Symptoms that fall within the red zone are more severe and need prompt attention.

In addition to the Action Plan, the Self-Care: Following Your Treatment Plan and Dealing with Your Symptoms booklet was given to each participant. This booklet is a sixteen page easy-to-read guide that focuses on self-care. It is designed to assist the patient with HF self-management. It addresses the importance of their treatment plan, helpful tips in following their health care provider's instructions, and assessing their own HF symptoms. The last page in the booklet is a log for daily weights. The information was created by and is available via the Heart Failure Society of America (HFSA, 2006). This booklet was used to help guide the project coordinator in creating the heart failure assessment questionnaire (Appendix I) used in this project.

A letter of support was obtained from the West Virginia Heart and Vascular Institute, the site of the intervention, by the project coordinator. A meeting with the office manager and the project coordinator was held to discuss mutual expectations, practice norms, patient population, and the best way to identify prospective participants.

The project proposal was presented to and evaluated by the project coordinator's committee prior to submission to the Institutional Review Board (IRB). Once the IRB approval was obtained the project was implemented. 
Phase II- Project Preparation. The project coordinator prepared all necessary tools and supplies that were utilized throughout the project. All literature was evaluated prior to implementation of the project for appropriate health literacy level.

Participating physicians, their staff, and allied health members were provided information about the project to ensure they had an understanding of how it was going to work. The staff was also informed that there may be an increased number of phone calls as a result of the project and how to direct the calls. Literature that was used for participant educational purposes was also shared to the physicians and staff.

Phase III- Project Implementation. Patients were identified by reviewing the office schedule, with the office manager, over a five-week time period. The patients who had a diagnosis of HF, an upcoming appointment, and a hospital admission for HF within the previous six months, were flagged as potential participants.

Once the potential participants were identified, the project coordinator met with the patients at WVHVI on days that correlated with their already scheduled appointments. At that time the project was discussed with the patient. If the patient agreed to participate, consent was signed.

The patient's understanding of HF was obtained using the heart failure assessment questionnaire (Appendix I) that was created by the project coordinator. Following the initial discussion and assessment, a laminated copy of the action plan and the HFSA SelfCare booklet (HFSA, 2003) were provided to the patient. A baseline MLHFQ (Appendix B) was also completed.

Each participant was assigned a number in order to assure anonymity and a project folder was started for each participant in order to keep data together. The project 
folders included: demographical information sheet (see Demographic Sheet in Appendix J), baseline MLHFQ (Appendix B), initial HF assessment findings (Appendix I), a copy of the responses from each weekly telephone intervention (Appendix E), and patient satisfaction survey (Appendix G).

A time was established for the first telephone call which was made within a week of the first initial office visit. Telephone calls were made weekly for six weeks for a total of six calls. During each call the pre-scripted telephone intervention (Appendix E) was used to ask questions based on the guidelines set forth by the AHA and HFSA.

After completion of the last telephone intervention an additional MLHFQ (Appendix B), heart failure assessment questionnaire (Appendix I), and patient satisfaction survey (Appendix G) were administered via phone. Upon completion of the intervention and data collection the staff was also given a satisfaction survey (Appendix H) to complete.

\section{Time and Resources}

The project took place in an established local cardiology practice. Costs for this project were minimal because the practice allowed the project coordinator to utilize space in their office in order to make telephone calls to the participants as necessary. There was laminating costs for the HF tool that was given to each participant and was approximately forty dollars total. All other copies and office supplies were provided by the participating practice.

The time commitment was minimal for participating physicians and their allied health professionals as their role was to provide HF care as usual. The office RN's and staff's time commitment was also minimal as they continued with usual day-to-day 
procedures of answering patient phone calls and triaging patients. The office RN was to document telephone encounters as usual in the patient's record even if any were calls were from patients participating in the project. Patient recruitment began with the implementation and due to time constraints, ceased 30 days after the initial implementation. The project ended once the last enrollee received his or her final telephone intervention and a post MLHFQ, post HF assessment questionnaire, patient and staff satisfaction surveys were completed.

\section{Evidence of Key Site Support}

The process to implement the intervention began at the beginning of the doctoral program and was ongoing until IRB the capstone project proposal was presented to the committee, submitted to and approved by the IRB. Once the project was implemented, the goal was to obtain 25 enrollees. Once the process of enrollment was completed, data collection was ongoing until the patients had received their final intervention and completed the final MLHFQ (Appendix B), HF assessment questionnaire (Appendix I) and satisfaction survey (Appendix G). The board certified physicians in the cardiology practice were willing to assist in the project and supported it by writing a letter of support. Due to the significance of heart failure in the community and in this practice along with the minimal cost of the project, feasibility of the project was greater than $95 \%$.

\section{Evaluation}

When the HF assessment questionnaire (Appendix I) was designed, the goal was to have the ability to assess patients' beliefs about their illness by the use of questions that relate to self-management. It is important to understand the patients' level of knowledge and beliefs about their illness because, based on the theory of Health Belief, 
behaviors are determined by a person's beliefs and perceptions. The HF assessment questionnaire addresses specifics such as "I keep all my scheduled doctor's appointments" and "I know when I should call my doctor about my symptoms." These types of questions required a response based on a five-point Likert-type scale with one indicating "never" and five indicating "all of the time or always." It is implied that if the response is "never" then the patient may have a perceived barrier or not understand the benefits of the recommended treatments. If patients are informed or given "cues to action" via the weekly telephone intervention it is expected that the scores will improve after the telephone intervention.

The Minnesota Living with Heart Failure Questionnaire (MLHFQ) was used to measure each patient's quality of life before and post-intervention (see the MLHFQ in Appendix B). The questionnaire was designed by physicians and nurses at the University of Minnesota in 1984 as a measurement tool for HF symptom and treatment effects. It is disease specific and consists of 21 questions using a six-point Likert scale. It is recommended by the creators of the questionnaire that when patient responses are scored they should be evaluated on symptom type (physical and psychological) and as a whole. Lower scores mean fewer symptoms and a better quality of life. A license to use the MLHFQ (Appendix B) was obtained by the project coordinator on September $9^{\text {th }}, 2009$ and is numbered A20100152 (Appendix C).

A prescripted telephone interview was created by the project coordinator based on recommendations for education and skill building obtained from the HFSA's guidelines (see Appendix E). Questions were designed to focus on complications associated with HF and self-care. Throughout the interview process patients were also provided educational 
information about what to monitor in self-management of their HF such as weight gain, blood pressure control, swelling, sodium intake, shortness of breath, medication adherence, fatigue, and activity level. The intervention was designed to reinforce selfmanagement behaviors by repeatedly providing the same information over a six-week time period.

\section{Project Objectives}

The project objectives help one to better understand, justify, and explain the capstone project. They were used to guide the implementation and evaluation of the project. According to the HBM theory, patients who better understand their illness and its severity are more likely to adhere to treatment regimens because they see them more as a benefit than a barrier (Bennett et al, 2005). This theory was used to guide the project coordinator in setting the three main objectives: to 1) increase patient awareness about their illness, 2) improve self-management, and 3) improve their quality of life.

Patient adherence is at great risk when there is little knowledge about their illness or treatment regimen provided to them (van der wal, Jaarsma \& van Veldhuisen, 2004). The first objective was to increase patient awareness about their HF via a weekly telephone intervention. This was measured by comparison of the baseline and post-intervention heart failure assessment questionnaire (Appendix I) responses. The second objective was to improve self-management. Comparison of the baseline and post-intervention HF assessment questionnaire (Appendix I) were also used for measurement. The third objective was to improve the patients' quality of life. The MLHFQ (Appendix B) is a widely used disease-specific tool for measurement of quality of life in HF patients. 
Comparison of baseline and post-intervention responses were used to measure this objective.

The project coordinator evaluated the project in three ways as follows: 1) data from the MLHFQ (Appendix B) were totaled based on patient responses prior to and following the six-week telephone intervention 2) data from the HF assessment questionnaire (Appendix I) were also totaled prior to and after the intervention 3) patient and employee satisfaction surveys (Appendices $\mathrm{G} \& \mathrm{H}$ ) were totaled after completion of the intervention. Patients' understanding of HF was evaluated by comparing the HF assessment questionnaire (Appendix I) responses at baseline and following the six-week telephone intervention. Baseline and post-telephone intervention MLHFQs (Appendix B) were compared to evaluate improvement of the participant's quality of life. The MLHFQ (Appendix B)can be divided into physical and psychological subscales. Feasibility of the project was evaluated and is discussed in detail under the "implications for practice section of this paper". Patient and staff satisfaction surveys were evaluated for a positive versus negative response only. Additional office telephone encounters, office visits, and hospital HF admissions did not occur during this project but would have been and further evaluated on an individual basis.

Once the data analysis was completed the findings were reported and presented to the capstone committee for final approval and review. The preliminary results postintervention were presented to the physicians at WVHVI individually. A written report was also provided once the committee authorized approval.

In order to determine whether or not a program was beneficial, a form of evaluation was developed. Results of the baseline and post-intervention questionnaires 
were reviewed at the end of the project to determine whether patients had increased knowledge of HF, better perception about their care, and improved self-management and quality of life. This was measured by comparing the MLHFQ (Appendix B) and HF assessment questionnaires (Appendix I) that were completed prior to and following the intervention. If a patient's individual scores are lower on the MLHFQ after the intervention, one might surmise that the patient was experiencing fewer symptoms due to his or her HF.

The HF assessment questionnaire (Appendix I) that was created specifically for this project was found to have several flaws. When the tool was designed, more thought should have been given on how the results would be scored. This only became apparent after the project was completed and data analysis began. The scale was designed to give results such as "never" and "always" which are not realistic as most people don't usually do a specific task to either extreme. There were also two questions that addressed habits of smoking and alcohol use. Both responses are derogatory for a patient with HF. When scores were totaled, the more a patient did each of these, the higher the score which interferes with the true outcomes. Additionally, the question of whether someone's diabetes is under control affects the scores inappropriately because all patients are not diabetic and those who were would have higher scores due to their co-morbidity. For these reasons, three items were removed from the analysis.

The method of statistical evaluation for this project was the paired sample T-test and the Wilcoxen Rank Test. The paired sample t-test is a parametric test often used to compare two groups based on a dependent variable and is highly effective in the removal of extraneous variability created by pre-existing individual differences (Polit and Beck, 
2010). With the paired samples t-test each individual serves as his or her own control.

The Wilcoxen Rank Test is the non-parametric equivalent of the paired t-test and is used to reinforce study results. The data obtained was put into the commonly used statistical analysis program Statistical Packages for Social Sciences (IBM, [SPSS] 2010) for further evaluation and comparison.

\section{Project Results}

There were a total of 19 patients recruited for this project. Three were lost due to attrition. The mean age of the patients in the study was 71 . Male patients represented $62.5 \%$ of the population and females represented $31.3 \%$. Of the 16 patients that participated $56.3 \%$ were white non-Hispanic, $31.3 \%$ were black or African-American, and $12.5 \%$ were Asian. More than half of the sample had a 12 th grade education, $31.3 \%$ were college graduates, and 6.3\% (one patient) had a Masters level degree or higher. One fourth of the patients reported living alone. When asked if they eat most of their meals at home $87.5 \%$ reported yes and $12.5 \%$ reported no. Fifty percent of the patients reported that they cook their own meals. No patients reported having difficulty reading or hearing. However, one patient reported having difficulty understanding written information. All patients had a home phone and all but two patients had a cell phone that had good reception at their home.

All patients had a hospital admission for heart failure within the past six months but it was unclear whether this was an exacerbation or new diagnosis. All patients reported having a co-morbidity of hypertension and seven patients also had a comorbidity of diabetes. Based on the New York heart Association heart failure 
classification system $18.8 \%$ were in functional class I, 50\% were in functional class II, and $31.3 \%$ were in functional class III.

The two questionnaires utilized for this project were tested for internal consistency and reliability using Cronbach's alpha coefficient. The MLHFQ has 21 questions and received a Cronbach's alpha score of .96 which suggests that all the questions are measuring the same thing and is highly reliable. The heart failure questionnaire that was designed specifically for this project had a Cronbach's alpha score of .84 when all 17 questions were measured. Although this does show reliability and internal consistency, these were improved when three concerning questions were removed from the equation resulting in a Cronbach's alpha score of .94 .

As mentioned previously, responses on both questionnaires used a Likert or Likert-type scale. The MLHFQ has a six point Likert scale in which "no" was represented by zero and "very much" was represented by the number five. The heart failure assessment questionnaire used a five point Likert scale with one being "never" and five being "all of the time/always". In order to compare the mean scores for the same group prior to and after the intervention, a paired-samples T-test was done based on the responses given in both questionnaires at two different times.

Increased patient awareness about HF and improved self-management were measured by comparing the baseline and post-intervention responses on the HF assessment questionnaires (Appendix I). Results revealed a mean score of $\mathrm{M}=46.0$ (SD $=8.981)$ pre-intervention and $\mathrm{M}=57.06(\mathrm{SD}=5.543)$ post-intervention when three questions were removed from the equation. However, when these three questions were factored back into the equation, the mean score was found to be $\mathrm{M}=51.25(\mathrm{SD}=8.760)$ 
pre-intervention and $\mathrm{M}=61.50(\mathrm{SD}=7.090)$ post-intervention. Both results revealed an increase in scores $t(d f 15)=-9.507, \mathrm{p}$ value $=<.001$ and $t(d f 15)=-8.335, \mathrm{p}$ value $=<$ .001 respectively. The mean difference in scores without the additional questions was $-11.063(\mathrm{SD}=4.654)$ and $-10.250(\mathrm{SD}=4.919)$ with the additional questions both with a $95 \%$ confidence interval ranging from -13.543 to -8.582 and -12.871 to -7.629

respectively. The increase in scores (with and without the three additional questions) was statistically significant.

Based on the results of the paired samples t-test, the mean score for the MLHFQ that measured improved quality of life, pre-intervention group was $(\mathrm{M})=34.88$, standard deviation $(\mathrm{SD})=15.126$ and $\mathrm{M}=32.06(\mathrm{SD}=16.405)$ for the post intervention group. These findings reveal a decrease in total scores following the telephone intervention $t(d f$ $15)=2.005, \mathrm{p}$ value $=.063$ which is not statistically significant. The mean score difference was $\mathrm{M}=2.813$ with a $95 \%$ confidence interval ranging from -.178 to 5.803 . The two sub-scales of physical symptoms and psychological symptoms were also analyzed. The mean score for the pre-physical symptoms group was $M=29.50$ ( $\mathrm{SD}=$ 11.736) and $\mathrm{M}=26.88(\mathrm{SD}=12.176)$ for the post-intervention group which also revealed a decrease in scores post-intervention $t(d f 15)=2.808, \mathrm{p}$ value $=.013$ which reveals statistical significance. Mean difference in score for the subscale group only looking at physical symptoms was 2.625 with a $95 \%$ confidence interval that ranged from .632 up to 4.618. The subscale group for psychological symptoms revealed $\mathrm{M}=5.88(\mathrm{SD}=3.964)$ pre-intervention and a post-intervention mean score of $\mathrm{M}=5.19(\mathrm{SD}=4.520)$. These findings also showed non-statistical significant decrease in scores following the telephone 
intervention $t(d f 15)=1.243, \mathrm{p}$ value $=.233$. The difference in mean score in this subscale was .688 with a confidence interval of $95 \%$ ranging from -.492 to 1.867 .

The nonparametric equivalent for the paired t-test is the Wilcoxen Rank Test which ranks the absolute difference between scores (Polit \& Beck, 2008). Similar findings were found in all but one group when compared to the paired t-test results. Both $\mathrm{HF}$ assessment questionnaires revealed similar results in comparison to the paired t-test findings. The HF assessment questionnaire without the additional three questions revealed, $\mathrm{Z}=-3.429, \mathrm{p}=.001$. When the three questions were factored back in to the equation again, similar results were found, $Z=-3.422, \mathrm{p}=.001$. Again, both were statistically significant.

In the MLHFQ groups pre and post-intervention $Z=-2.330, \mathrm{p}$ value $=.020$ which is statistically significant unlike the findings with the paired t-test which was not statistically significant $(\mathrm{p}=.063)$. The subscale groups of the MLHFQ revealed similar results in comparison with the physical symptom group having, $Z=-2.423, p=.015$ and the psychological group revealing, $\mathrm{Z}=-1.663, \mathrm{p}=.102$.

Based on improved scores on the heart failure questionnaire post-intervention, participants did have increased awareness following the intervention. The statistically significant scores also infer that improved self-management was also evident postintervention. Although not statistically significant, baseline MLHFQ scores improved post-intervention which implies improved quality of life. All findings were positive in supporting a nurse-led telephone intervention can be beneficial to HF patients.

Improved scores are likely due to the repetitive nature of the project and the project coordinator was providing the intervention on a regular basis. Patients were also 
key facilitators in the success of obtaining all three goals because they were available for the weekly intervention and willing participants. Patient and staff satisfaction surveys revealed that all involved were satisfied and believed the intervention to be beneficial.

\section{Discussion}

Because the Health Belief Model theory is widely used in health education and promotion, it was chosen as the theoretical framework for this capstone project. This theory helps to explain why people behave the way they do especially when they engage in non-adherence of treatment recommendations. Based on the HBM there are many other factors that contribute to this type of behavior such as patients don't perceive susceptibility, lack of awareness to the seriousness and treatment benefits, and barriers to care. Results from this project support that providing patients with cues to action can increase self-efficacy, alleviate barriers, increase awareness about disease severity and treatment benefit. Improving self-management, quality of life, and increase awareness and knowledge in patients with heart failure was the purpose of this capstone project. A six week nurse-led telephone intervention was chosen as the intervention because the literature supported it as an effective way to improve outcomes in patients with HF. The Health Belief Model was selected to guide the project because the intervention focused on health promotion and the conceptual framework seemed applicable and had been used in similar studies.

Approximately 30 patients were asked about participation but, only 19 agreed and three of those patients were lost to attrition. One might think that those who chose not to participate had barriers that interfered or didn't understand either benefits to treatment or the possible severity of their illness. Out of the 16 active participants, $62.5 \%$ were males, 
31.3\% were females, $56.3 \%$ were White, $31.3 \%$ were Black and $12.5 \%$ were Asian. All patients were over the age of 65. A study done by Weissfeld, Kirscht, and Brock (1990) in which data analysis adjusted for perceived levels of health, found that Blacks and people of a low-socioeconomic status have more favorable health beliefs especially in relation to health promotion. Women in this study reported being sick more often and the severity of their illnesses were greater. Those who reported greater importance on personal health habits were women, black, older and of lower socioeconomic status. Although this capstone project had a small sample size and did not analyze perceived levels of health, age, gender and race can't be excluded as modifying factors.

Eighty-seven percent of participants reported that they ate most of their meals at home. One could imply that it is because people have been well-informed and do it because it is easier when trying to manage sodium restrictions. This implication supports the HBM theory that when cues to action are provided self-efficacy can be improved.

Comparison of the MLHFQ scores from baseline to post-intervention revealed that patients reported fewer overall HF symptoms following the six-week telephone intervention. However, it was not statistically significant. One could presume lower scores were directly related to the knowledge gained by the intervention and resulted in improved self-management. This finding would be supported based on the HBM. One would suspect that the reduction in the psychological symptom scores would have been statistically significant and the physical symptoms would have not been postintervention. This was not the finding in this study and may be because some patients became more worried once they were aware of the severity of their illness. The HBM supports that perceived severity affects health beliefs. 
When the HF questionnaire was designed, it was based on questions that would give the project coordinator a better understanding of the patients' knowledge about their health beliefs and awareness of disease management strategies. Even with the concerns about three specific questions, analysis of pre and post-intervention scores found there were statistically significant improvements. The intervention addressed possible barriers such as medication adherence and provided education on the importance of daily weights, sodium restrictions, monitoring symptoms and complications. It could be inferred that the improved scores were a direct result of the intervention and led to improved self-efficacy. According to the HBM conceptual framework, if perceived barriers are addressed and strategies (such as the intervention) are implemented, self-efficacy can improve (Rosenstock et al, 1988).

\section{Recommendations}

\section{Practice Implications}

Even with several statistically significant findings, not all interventions are feasible in a clinical practice due to time constraints and cost-effectiveness. There were few studies reviewed that indicated that a nurse-led telephone intervention was cost effective (Gonseth et al, 2004 \& Clark et al, 2007). This particular capstone project would not be financially beneficial to this local cardiology practice as it was more time consuming than expected and is not a billable service. It was anticipated that each phone call would take approximately 15-20 minutes. However, in reality, each call consumed about 20-30 minutes. It is likely because many of the patients were not prepared for the call and took longer time to answer the questions than expected. When given the opportunity to ask questions at the end of the session, several of the patients wanted to 
discuss particular situations and often had to be redirected back to the purpose of the intervention. One explanation for this type of behavior in this patient population may have been lonely and just wanting someone with whom to speak. Another reason may have been that the patients did not feel like they had time during regular office visits to discuss all their questions and or concerns.

The Center for Medicare and Medicaid Services (Center for Medicare and Medicaid Services [CMS], 2012) does not reimburse for telephone services. The majority of the patients in this particular practice are 65 years of age and older and have Medicare as their primary payer source. However, CMS does reimburse for a once a year intensive behavioral therapy visit for patient's with cardiovascular disease. This local cardiology practice would qualify for such a visit because they are an internal medicine practice.

In addition to the intensive behavioral therapy for cardiovascular disease, this practice can also benefit from seeing patients every 3 to 4 months using the billing code 99212, 99213 or 99214 as deemed appropriately. During these visits, questions and HF information similar to the intervention could be addressed. However given time constraints, the information would need to be condensed. By providing this service for HF patients practice revenue could be increased and patients would likely have better symptom management, quality of life, and adherence to treatment recommendations. Even if the practice hired an additional provider for just CHF patients, the service would be justified and financially beneficial.

Based on analysis of specific responses given by the patients, pre and postintervention, this particular practice should focus on ways to improve patient knowledge about medications, symptom management, and plan of action. Prior to the intervention 
only three participants responded "almost always" when asked if they monitor for swelling. Post-intervention 12 participants responded "almost always" when posed with the same question. When asked "I know what to do when I get short of breath" 10 patients responded "almost always" or "always" prior to the intervention but all 16 reported the same response following the intervention. Patients also reported improvement of being able to list their HF medications and why they take them postintervention. Patients reported improvement post-intervention when asked if they knew who to call with questions, reduce salt in their diet, recorded daily weights, and overall knowing how to manage their HF.

The HBM conceptual framework was applicable in all aspects for this population. Although all of the participants already had a diagnosis of heart failure, some of their responses to questions can lead one to believe that there was lack of perceived susceptibility that their condition could worsen. Concepts of perceived severity, benefits and barriers were also applicable in this population and were found to be a good guide for the project. It is likely that based on the lack of adherence to daily weights, sodium restrictions and symptom monitoring by the participants prior to the intervention was based on the lack of perceived severity or benefit. Another possibility is that patients might have had perceived barriers but once they were addressed and the patient was more informed, this was no longer their perception. Project results strongly support the HBM concepts that providing cues to action via a telephone intervention was likely beneficial and can improve self-efficacy.

This particular organization has a goal to incorporate a heart failure and lipid clinic into their practice. The physicians, nurse practitioners, physician assistants, 
registered nurses, billing staff, and office manager need to be involved to ensure that the goals of the clinic are based on appropriate interventions and cost-effective.

\section{Limitations}

Results of the project were positive as there were improved scores on the HF assessment tool designed to evaluate patients' awareness and self-management. As mentioned earlier, this questionnaire did have some flaws. There were three statements that could have possibly affected the outcomes if they were not removed. They were; "I smoke", "I drink alcohol", and "my diabetes is under control". Even though this information is important to know when treating HF patients, the way it was presented in this study was not correct. The HF assessment questionnaire used a five-point Likert-type scale and the way the questions were arranged allowed the patient to score higher the more they smoked and drank alcohol, neither which is good for someone with heart failure. Diabetes did not pertain to all subjects but gave a higher score possibility if the patient did have it. The problems were not evident when the assessment tool was being designed but emerged when the data was analyzed. Fortunately, the findings were statistically significant when analyzed with and without statements that were of concern because comparison was done for pre and post-intervention and the subjects were their own control.

Positive results were welcomed, but, there were still several limitations of this particular study. The sample size was small with only 16 participants. The time it took to do the intervention was greater than expected. The intervention itself is not feasible in this setting as it is time consuming. It was also not cost effective as it is not a billable service. 
It is unfortunate that CMS does not reimburse for this type of service because based on the results, the intervention was beneficial to the participants. One perceived barrier could be access to care and may be a result of lack of providers or inability to get to the provider. If there was reimbursement for this type of service patients may have improved self-management and ultimately spend less time in the hospital. According to the CDC (cite), the average length of stay for a HF patient was 5.3 days which is far more costly. Heart failure costs could be decreased if patients are provided with proper education, better adherence to recommended treatments, and removal of perceived barriers, all which can be improved with simple strategies such as the telephone intervention used in this project.

This study was successful in revealing that a nurse-led telephone intervention can be effective to improve patients' knowledge about their illness, improve selfmanagement, and ultimately improve quality of life. However, the project did not conclude that the intervention was cost-effective. Based on the improved outcomes it is recommended that patients receive some type of repetitive intervention that focuses on their HF symptoms and appropriate self-management. This could be incorporated into their routine follow-up visits. This type of intervention could easily be applied to any particular illness and in an array of settings. It is not uncommon that a patients' family doctor may manage their heart failure. Educational materials should also be provided to general practitioners so they could also reinforce the benefits of treatment recommendations. 


\section{Conclusion}

Heart failure is a potentially fatal illness that is increasing in prevalence and has a high mortality rate. Disease etiology and co-morbidities influence prognosis. Heart failure patient hospital admissions and readmissions have been increasing rapidly with eight percent of those admitted with heart failure being readmitted within three months after discharge due to exacerbation of the disease. Improvements in treatment and management of heart failure should focus on improved self-management by increasing access to care, enhancement of patient knowledge about their disease, and overall improvement in quality of life.

The objectives of this capstone project were to 1) increase patient awareness about their illness, 2) improve symptom management, and 3) improve their quality of life by utilizing a nurse-led telephone intervention on a weekly basis for six weeks following a hospitalization for HF within the past six months. This project provided participants with education about HF and a guide to help with self-management via the six telephone interventions. Based on the favorable results, the objectives were likely met in this sample of the population. The literature also supports that education, nurse-led interventions, and outpatient specialty clinics can improve outcomes and ultimately decrease hospital admission and readmission rates for HF. Heart failure patients in WV are at high risk due to increased age. The Appalachian culture and its fear of treatment, lack of access and knowledge can create barriers for these patients. Perceptions about the illness can be displayed in many ways as demonstrated by the Health Belief Model. Concepts of this model such as; perceived susceptibility, perceived severity, perceived threat, perceived barriers, and perceived benefits were used to guide this project. Based 
on the HF assessment questionnaire scores post-intervention (Appendix I), participants improved their awareness of HF and self-management. This capstone project confirmed that providing cues to action can improve outcomes as supported by the HBM.

\section{Attainment of Leadership Goals}

Prior to starting the capstone project, it was not clear how the project was going to assist me in attaining any further goals. As I look back to the early stages of the project and now at the final stage, it is evident that there are many leadership goals that have been attained. I better understand heart failure and how life's processes can influence behaviors and outcomes. This information is valuable when caring for patients and will allow me to be better understanding when patients are not adhering to recommended treatments.

Actively participating in the project has given me a better appreciation for the importance of research in practice. It has given me a foundation of how to evaluate a program that may or may not be beneficial to patient outcomes. In the future, I would like to be more involved in evidenced-based medicine and this project has provided me with insight on how to do it. 


\section{References}

AGREE collaboration (2001). Appraisal of guidelines for research and evaluation (AGREE) instrument. Retrieved from www.agreecollaboration.org

American Heart Association (AHA). (2012). Executive Summary: Heart Disease and Stroke Statistics-2012 Update. Circulation, 125, 188-197.

doi: 10.1161/CIR.Ob013e3182456d46

American Heart Association (AHA). (2009) Focused update: ACCF/AHA

Guidelines for the diagnosis and management of heart failure in adults: a report of the American College of Cardiology Foundation/AHA task force on practice guidelines: developed in collaboration with the international society for heart and lung transplantation. Circulation, 119, 1977-2016.

doi: 10.1161/CIRCULATIONAHA.109.192064

American Heart Association (AHA). (2006). Heart disease and stroke statistics-2006 update. Retrieved from www.americanheart.org

American Public Transportation Association (APTA). (2009). West Virginia transit links. Retrieved from http://www.apta.com/links/state local/wv.cfm\#A25

Appalachian Regional Ministry. (2011). The Appalachians.

Retrieved from www.arministry.org/appalachianculture.asp\#Culture

Baker DW, Parker MR, Williams MV, Ptikin K, Parikh NS, Coates W, Imara M. 1996.

The health care experience of patients with low literacy. Archives of Family Medicine, 5(6): 329-334.

Baker, D.W., Wolf, M.S., Feinglass, J., Thompson, J.A., Gazmararian, J.A. et al. (2007). Health literacy and mortality among elderly persons. Archive 
of Internal Medicine, 167,1503-1509.

Battersby, J., Holland, R., Harvey, I, Lenaghan, E, Smith, J. and Hay, L. (2005).

Systematic review of multidisciplinary interventions in heart failure. Heart, 99, 899-906.

Behringer, B., Friedell, G.H., Dorgan, A., Hutson, S.P. et al. (2007). Understanding the challenges of reducing cancer in Appalachia: addressing a place-based health disparity population. Californian Journal of Health Promotion, 5, 40-49.

Bennett, S. J., Hays, L. M., Embree, J. L. and Arnould. (2000). Heart messages: a Tailored message intervention for improving heart failure outcomes. Journal of Cardiovascular Nursing. 14, 94-105.

Bennett, S. J., Lane, K. A., Welch, J., Perkins, S. M., Brater, D. C., and Murray, M. (2005). Medication and dietary compliance beliefs in heart failure. Western Journal of Nursing Research. 27, 977-993. doi: 10.1177/0193945905280253

Bhatia, R.S, Tu, J.V, Lee, D.S., Austin, P.C., Fang, J., Haouzi, A. et al. (2006). Outcome of heart failure with preserved ejection fraction in a population-based study. The New England Journal of Medicine, 355, 260-269.

Bibbins-Domingo, K., Chertow, G.M., Fried, L.F., Odden, M.C., Newman, A.B., Kritchevsky, S.B. et al. (2006). Renal function and heart failure risk in older black and white individuals. Archives of Internal Medicine, 166, 1396-1402.

Caldwell, M.A., Peters, K.J. \& Dracup, K.A. 2005. A simplified education program improves knowledge, self-care behavior, and disease severity in heart failure patients in rural settings. American Heart Journal, 150, 983 e.7-983 e12. 
Center for Disease Control (CDC). (2009). National Center for Health Statistics. Retrieved from www.cdc.gov/nchs/data/hdasd/sr13 156t9.pdf

Clark, R.A., Inglis, S.C., McAlister, F.A., Cleland, J.G., Stewart, S. 2007. Telemonitoring or structured telephone support programmes for patients with chronic heart failure: systematic review and meta-analysis. Retrieved from: www.bmj.com October 11, 2008. doi: 101136/bmj.39156.536968.55

Cleland, J.G., Louis, A.A., Rigby, A.S., Janssens, U., Aggie, H.M. \& Balk, M. 2005. Noninvasive home telemonitoring for patients with heart failure at high risk of recurrent admission and death. Journal of the American College of Cardiology, 45, 1654-64. doi: 1016/j.jacc.2005.01.050

Coyne, C.A., Demian-Popescu, C., and Friend, D. (2006). Social and cultural factors influencing health in southern West Virginia: a qualitative study. Retrieved from www.cdc.gov/pcd/issuses/2006/oct/pdf/06_0030.htm

Deskins, S., Harris, C.V, Bradlyn, A.S., Cottrell, L., Coffman, J.W., Olexa, J. et al. (2006). Preventive care in Appalachia: use of the theory of planned behavior to identify barriers to participation in cholesterol screenings among West Virginians. The Journal of Rural Health, 22, 367-374.

Ellenbogen, K.A., Kay, G.N., Wilkoff, B.L. (2004). Device Therapy for Congestive Heart Failure. Philadelphia, Pennsylvania: Saunders.

Fonarow, G.C., Yancy, C.W., Albert, N.M., Curtis, A.B., Stough, W.G., Gheorghiade, M. et al. (2007). Improving the use of evidence-based heart failure therapies in the outpatient setting: the IMPROVE HF performance improvement registry. American Heart Journal, 154, 12-38. 
Fonarow, G.C., Albert, N.M., Curtis, A.B., Stough, W.G., Gheorghiade, M., Hewyood, J.T. et al. (2010). Improving evidence-based care for heart failure in outpatient Cardiology practice: primary result of the registry to improve the use of evidenceBased heart failure therapies in the outpatient setting (IMPROVE HF). Circlulation, 122, 585-596. doi: 10.1161/CIRCULATIONAHA.109. 934471

Friedman, M. and Quinn, J.R. (2008). Heart failure patients' time, symptoms, and actions Before a hospital admission. Journal of Cardiovascular Nursing, 6, 506-512. GESICA Investigators (2005). Randomized trial of telephone intervention in chronic heart failure: DIAL trial. Retrieved October, 20, 2008, from www.bmj.com doi:10.1136/bmj.38516.398067.EO

Goldacre, M.J., Mant, D., Duncan, M. and Griffith, M. (2005). Mortality from heart failure in an English population, 1979-2003: study of death certification. Journal of Epidemiology in Community Health, 25, 249-253. doi: 10.1136/jech.2004.028951

Gonseth, J., Guallar-Castillon, P., Banegas, J.R., \& Rodriquez-Artalejo, F. 2004. The effectiveness of disease management programmes in reducing hospital re-admission in older patients with heart failure: a systematic review and meta-analysis of published reports. European Heart Journal, 25, 1570-1595. doi: 10.1016/j.ehj.2004.08.004

Greenberg, B., Quinones, M.A., Koilpillai, C., Limacher, M., Shindler, D., Benedict, C. et al. (2005) Effects of long-term enalapril therapy on cardiac structure and function in patients with left ventricular dysfunction: results of the SOLVD echocardiography substudy. Circulation, 91, 2573-2581. 
Halverson JA, Barnett E, Casper M. (2002). Geographic disparities in heart disease and stroke mortality among black and white populations in the Appalachian region. Ethnicity and Disease,12, S3-82-91.

Heart Failure Society of America, (2012). Retrieved from: www.abouthf.org/questions_stages.htm

Heart Failure Society of America, (2003). Retrieved from: www.hfsa.org/pdf/module4.pdf

Heart Failure Society of America, (2010). Focused Update: ACCF/AHA Guidelines for the diagnosis and management of heart failure in adults. Retrieved from http://circ.ahajournals.org doi: 10.1016/j.cardfail.2010.04.005

Huttlinger, K., Schaller-Ayers, J. and Lawson, T. (2004). Health care in Appalachia: a population-based approach. Public Health Nursing, 21, 103-110.

IBM. (2010). Statistical packages for the social sciences. Retrieved from http://www.spss.com/

Institute of Medicine (IOM). (2004). Health literacy: a prescription to end confusion Retrieved from www.iom.edu/Reports/2004/Health-Literacy-A-Prescripition-toend-confusion.aspx

Jaarsma, T., van der Wal, M. H., Lesman-Leegte, I., Luttik, M.L., Hogenhuis, J., Veeger, N.J. et al. 2008. Effect of moderate or intensive disease management program on outcome in patients with heart failure. Archives of Internal Medicine, 168, 316-324.

Jadad, A.R., Moore, R.A., Carroll, D., Jenkinson, C., Reynolds, D.J. et al. (1996) Assessing the quality of reports of randomized clinical trials: is blinding necessary? Control Clinical Trials, 17, 1-12. 
Joshi, A.V., D’Souza, A.O and Madhavan, S.S. (2007). Differences in hospital length-ofstay, charges, and mortality in congestive heart failure patients. Heart Failure, 10, 76-84.

Kannel, W.B. (2000). Incidence and epidemiology of heart failure. Heart Failure Reviews, 5, 167-173.

Munro, B. H. (2005). Statistical methods: for health care research. Chestnut Hill, Mass.: Lippincott, Williams and Wilkins.

National Center for Education Statistics (NCES) (2003). National Assessment of Adult Literacy (NAAL)-Health Literacy. Retrieved from http://nces.ed.gov/naal/health.asp

National Heart Association of Malaysia, Academy of Medicine and Ministry of Health (2007). Clinical Practice Guidelines in Heart Failure. Retrieved from http://www.malaysianheart.org/article.php?aid=276

National Heart Lung and Blood Institute (2011). Retrieved from http://www.nhlbi.nih.gov/health/dci/Diseases/HF/HF_Causes.html

Nielsen-Bohlman, L., Panzer, A.M., Kindig, D.A. (2004). Health literacy: a prescription to end confusion. Washington, DC: The National Academies Press.

Polit, D.F. and Beck, C.T. (2010). Essentials of nursing research: appraising evidence for nursing practice $7^{\text {th }}$ ed. (pp. 395-415). Philadelphia, PA: Lippincott Williams and Wilkins.

Rimer, B. and Glanz, K. National Cancer Institute. (2005). Theory at a glance: a guide for health promotion practice. Retrieved from http://www.cancer.gov/aboutnci/oc/theory-at-glance 
Rosenstock, I.M., Stretcher, V.J. and Becker, M.H. (1988). Social learning theory and the health belief model. Health Education and Behavior. 15, 175-183.

Sethares, K.A and Elliot, K. (2004) The effect of a tailored message intervention on heart failure on heart failure readmission rates, quality of life, and benefit and barrier beliefs in persons with heart failure. Heart and Lung, 33, 249-260.

doi: 10.1016/j.hrtlng.2004.03.005

Scottish Intercollegiate Guidelines Network (2008). Retrieved from http://www.sign.ac.uk/guidelines/audit/index.html

Sherwood, A., Blumethal, J.A., Trivedi, R., Johnson, K.S., O’Connor, C.M. et al. (2007). Relationship of depression to death or hospitalization in patients with heart failure. Archives of Internal Medicine, 167, 367-373,

Sherwood, A., Blumenthal, J.A., Koch, G.G., Dupree, C.S., Johnson, K.S. et al. (2011) Worsening depressive symptoms are associated with adverse clinical outcomes in patients with heart failure. Journal of the American College of Cardiology, 57, 418-423. doi: 10.1016/j.jacc.2010.09.031

Smith, S.L. and Tessaro, I.A. (2005). Cultural perspectives on diabetes in an Appalachian population. American Journal of Health Behavior, 29, 291-301.

United States Census. (2000). State and County Quick Facts. Retrieved from http://quickfacts.census.gov/qfd/states/54/54039.html

United States Census. (2010). State and County Quick Facts. Retrieved from $\underline{\text { http://quickfacts.census.gov/qfd/states/54/54039.html }}$

van der Pligt, J. (1996). Risk Perception and Self-Protective Behavior. European Psychologist, 1, 34-43. doi: 10.1027/1016-9040.1.1.34 
van der Wal, M.H., Jaarsma, T., Moser, D.K., van Gilst, W.H. and van Veldhuisen, D.J. (2010). Qualitative examination of compliance in heart failure patients in The Netherlands. Heart Lung, 39, 121-130. doi: 10.1016/j.hrtlng.2009.07.008

Volkova, N., McClellan, W., Soucie, M.J. and Schoolwerth, Anton. (2006). Racial disparities in the prevalence of cardiovascular disease among incident end-stage renal disease patients. Nephrology Dialysis Transplantation, 21, 2202-2209. doi: $10.1093 / \mathrm{ndt} / \mathrm{gfl078}$

Weissfeld, J.L., Kirscht, J.P. and Brock, B.M. (1990). Health Beliefs in a Population: The Michigan Blood Pressure Survey. Health Education Quarterly, 17, 141-155. 


\section{Appendix A}

\section{Event Budget for Capstone Project}

\section{Expenses for Capstone Project}

\begin{tabular}{|c|c|c|c|c|c|}
\hline \multirow{2}{*}{\multicolumn{3}{|c|}{ Total Expenses }} & & Estimated & Actual \\
\hline & & & & \multicolumn{2}{|l|}{ \#REF! } \\
\hline & Estimated & Actual & & Estimated & $\overline{\text { Actual }}$ \\
\hline \multicolumn{6}{|l|}{ Equipment. } \\
\hline \multirow{3}{*}{$\begin{array}{l}60 \text { digtal scales } 0 \$ 25.00 \\
\text { Photo copier (provided) } \\
\text { Telephones (provided) }\end{array}$} & $\$ 1,500,00$ & & \multicolumn{3}{|l|}{ Miscellaneous expenses } \\
\hline & $\$ 0,00$ & & & $\$ 100.00$ & \\
\hline & $\$ 0.00$ & & & & \\
\hline Totals & $\$ 1,500,00$ & $\$ 0.00$ & & & \\
\hline \multirow{2}{*}{\multicolumn{3}{|c|}{ Office supplics }} & \multirow{3}{*}{ Totals } & & \\
\hline & & & & $\$ 100.00$ & $\$ 0.00$ \\
\hline \multirow{4}{*}{$\begin{array}{l}\text { Color ink } 4 @ \$ 40.00 \\
\text { Black ink } 4 @ \$ 20.00 \\
\text { Lamination } 60 @ \$ 2.00 \\
\text { Pens and highlighters (donate }\end{array}$} & $\$ 0.00$ & & & & \\
\hline & $\$ 0.00$ & & \multicolumn{3}{|l|}{ Travel } \\
\hline & $\$ 160.00$ & & \multirow{2}{*}{$\begin{array}{l}\text { Samantha Stone (provided) } \\
\text { Patents (self-provided) }\end{array}$} & $\$ 0.00$ & \\
\hline & $\$ 0.00$ & & & 50,00 & \\
\hline 10 reams of paper @ $\$ 8.00$ & $\$ 0,00$ & & Totals & $\$ 0.00$ & $\$ 0,00$ \\
\hline Totals & $\$ 160.00$ & $\$ 0.00$ & & & \\
\hline Telephones (provided) & $\$ 0.00$ & & & & \\
\hline & & 800 & & & \\
\hline Totals & $\$ 0.00$ & $\$ 0.00$ & & & \\
\hline \multicolumn{3}{|l|}{ Site/lease } & & & \\
\hline \multirow{4}{*}{$\begin{array}{l}\text { WW Heart } \\
\text { Staffing } \\
\text { CAMC } \\
\text { TMH and SF }\end{array}$} & $\$ 0.00$ & & & & \\
\hline & $\$ 0.00$ & & & & \\
\hline & $\$ 0.00$ & & & & \\
\hline & $\$ 0.00$ & & & & \\
\hline Totals & $\$ 0,00$ & $\$ 0,00$ & & & \\
\hline
\end{tabular}




\section{Appendix B}

\section{MINNESOTA LIVING WITH HEART FAILURE ${ }^{\circ}$ QUESTIONNAIRE}

The following questions ask how much your heart failure (heart condition) affected your life during the past month (4 weeks). After each question, circle the $0,1,2,3,4$ or 5 to show how much your life was affected. If a question does not apply to you, circle the 0 after that question.

Did your heart failure prevent

you from living as you wanted during the past month ( 4 weeks) by -

\begin{tabular}{cc} 
Very & Very \\
No Little & Much \\
\hline
\end{tabular}

1. causing swelling in your ankles or legs?

2. making you sit or lie down to rest during the day?

3. making your walking about or climbing stairs difficult?

4. making your working around the house or yard difficult?

5. making your going places away from home difficult?

6. making your sleeping well at night difficult?

7. making your relating to or doing things with your friends or family difficult?

8. making your working to earn a living difficult?

9. making your recreational pastimes, sports or hobbies difficult?

10. making your sexual activities difficult?

11. making you eat less of the foods you like?

12. making you short of breath?

13. making you tired, fatigued, or low on energy?

14. making you stay in a hospital?

15. costing you money for medical care?

16. giving you side effects from treatments?

17. making you feel you are a burden to your family or friends?

18. making you feel a loss of self-control in your life?

19. making you worry?

20. making it difficult for you to concentrate or remember things?

21. making you feel depressed?

$\begin{array}{llllll}0 & 1 & 2 & 3 & 4 & 5 \\ 0 & 1 & 2 & 3 & 4 & 5 \\ 0 & 1 & 2 & 3 & 4 & 5 \\ 0 & 1 & 2 & 3 & 4 & 5 \\ 0 & 1 & 2 & 3 & 4 & 5 \\ 0 & 1 & 2 & 3 & 4 & 5 \\ 0 & 1 & 2 & 3 & 4 & 5 \\ 0 & 1 & 2 & 3 & 4 & 5 \\ 0 & 1 & 2 & 3 & 4 & 5 \\ 0 & 1 & 2 & 3 & 4 & 5 \\ 0 & 1 & 2 & 3 & 4 & 5 \\ 0 & 1 & 2 & 3 & 4 & 5 \\ 0 & 1 & 2 & 3 & 4 & 5 \\ 0 & 1 & 2 & 3 & 4 & 5 \\ 0 & 1 & 2 & 3 & 4 & 5 \\ 0 & 1 & 2 & 3 & 4 & 5 \\ 0 & 1 & 2 & 3 & 4 & 5 \\ 0 & 1 & 2 & 3 & 4 & 5 \\ 0 & 1 & 2 & 3 & 4 & 5 \\ 0 & 1 & 2 & 3 & 4 & 5 \\ & 1 & 2 & 3 & 4 & 5\end{array}$

(C1986 Regents of the University of Minnesota, All rights reserved. Do not copy or reproduce without permission. LIVING WITH HEART FAILURE® is a registered trademark of the Regents of the University of Minnesota.

$11 / 10 / 04$ 


\section{Appendix C}

\section{Minnesota LIVING WITH HEART FAILURE@ Questionnaire} COPYRIGH'Y USER'S LICENSE

The Regents of the University of Minnesota (hereafter referred to as "UNIVERSITY"), a constitutional corporation of the State of Minnesota having an office and principal place of business at 1000 Westyate Drive, Suite 160, St. Paul, MN 55114-8658 has created a copyrighted WORK entitled the Minnesota LIVING WITH HEART FAILURE: Questionnaire intended for use by authorized hoalth care professionals and researchers, and desires to make the WORK available for use worldwide.

Completion of this COPYRIGHT USER'S LICENSE ("LICENSE"), whereby the LICENSER agrees to the terms specified herein, is required to use the WORK. Users must legibly complete items $1.3,6.1,6.2$ and 7.2 , if applicable. A signature and date is also required on the last page prior to submitting this document as directed in item 7.1.

\section{ARTICLE I - DEFINITIONS}

1.1 WORK means the Minnesota LIVING WITH HEART FAILUREQ Questionnaire and Instructions for Data Collection and Searing. This WORK is in the English language, and is identified as U/M Docket \#94019. An electronic copy of the WORK and supplemental intormation including information about translations is available at www,milhfg,org.

1.2 APPROVBD COPIES means duplicates of the WORK that shall include the following statements:

O1986 Regents of the University of Minnesota, All rights reserved. Do not copy or reproduce without permission. LIVING WITH HEART FAILURBdo is a registered tradernark of the Regents of the University of Minnesota.

1.3 LICENSEE means (complete all of the following)

Name of person and organization: Samantha Stone

Address: 804 Hamilton Circle

Telephone number: 304-610-0058

Facsinuile number: $304-345-2420$

Electronic mail address: sstonecfnp@yahoo.com

\section{ARTICLE II - LICENSE}

2.1 UNIVERSITY grants to LICENSEB the right to reproduce the WORK and use APPROVED COPIES of the WORK for purposes deseribed below in Article 6.1 upon, (i) submission of a completed LICENSE to the UNIVERSITY, (ii) payment to the UNIVERSITY of the applicable nonrefundable LICNESE FEE specified below in Article 6.2, and (iii) notification of acceptance of (i) and (ii) by the UNIVERSITY. The EFFECTIVE DATE of this LICENSE is the date of (iii).

2.2 LICENSEE is granted no other license to or rights in the WORK other than as expressly stated in Article 2.1.

2.3 UNIVERSITY retains all rights in the WORK not granted to the LICENSEE under 2.1. UNIVERSITY retains ownership of the copyright to the WORK.

2.4 UNIVERSITY does not grant to LICENSBB any right to use the name or marks of the UNIVERSITY in any manner except as may be expressly provided in this LICENSB.

-1 of 4 . 
LICENSE \# 9/10/2009 11:16 AM

2.5 LICENSEB may not assign its license rights under this LICENSE to any entity other than a wholly-owned subsidiary of the LICENSEE.

\section{ARTICLE II - TERM AND TERMINATION}

3.1 The term of this LICENSE shall be from the ERFECTIVE DATE of this LICENSE specified in Article 2.1 until the LICENSEE completes or ceases use of the WORK described below in Article 6.1, or the UNIVERSITY terminates the LICENSE as described below in Article 3.2. However, in no event shall the term of this license exceed ten $(10)$ years.

3.2 UNIVERSITY may terminate this LICENSE upon breach of the LICENSE by LICENSEE. UNIVERSITY shall give LICENSEE written notice of the breach and notice of the intent to terminate. If LICENSEE does not cure the breach within thirty $(30)$ days of the notice, the LICENSE shall terminate. Upan such termination, LICENSEE's right to use the WORK shall terminate.

3.3 Termination of this LICENSE shall not extinguish any of LICENSEE's obligations under this LICENSE which, by their terms, continue after the date of such termination or expiration.

\section{ARTICLE IV - PROTECTION OF PROPRIETARY RIGHTS}

4.1 LICENSEE shall take all steps reasonable to protect UNIVRRSITY's ownership rights in the WORK. LICENSEE shall not distribute copies of the WORK to third parties or ernployees without appropriate notice, agreement, and/or instruction with respect to use, copying, modification, and copyright protection of the WORK.

4.2 LICENSEE will not remove the UNIVERSITY copyright notice and/or other proprietary notices.

\section{ARTICLE V - WARRANTIES AND LIMITATIONS; INDEMNIFICATION}

5.1 UNIVERSITY and LICENSEE warrant that they have the right to enter into this LICENSE and the ability to comply with its terms.

5.2 UNIVERSITY MAKES NO REPRESENTATIONS OR WARRANTIES, EXPRESS OR IMPLIED. BY WAY OF BXAMPLE, BUT NOT LIMITATION, UNIVERSITY MAKES NO REPRESENTATIONS OR WARRANTIES OF MERCHANTABLITY OR FITNESS FOR ANY PARTICULAR PURPOSE OF THE WORK. UNIVERSITY SHALL NOT BB HRID LIABLE FOR ANY LIABILITY OR FOR ANY INDIRECT OR CONSEQUENTLAL DAMAGES RBSULTING FROM THE USB OF THE WORK.

5.3 LICENSEE agrees to indermify and hold UNIVERSITY harmless against any claims or damages resulting from LICENSEE's use of the WORK including all liability to third parties arising from the negligence of LICENSEE. LICENSEE assumes no responsibility for any thind party claims that the WORK, unmodified by LICENSEB, infringes a copyright of the third party, or for damages arising from the willful or negligent behavior or conduct of UNIVERSITY. 
LICENSE \# 9/10/2009 11:16 AM

\section{ARTICLE VI-LICENSED USE OF WORK AND FEE}

6.1 The LICENSEE's use of the WORK under this LICENSE is restricted to uses indicated by an " $\mathrm{X}$ " in a box preceding each intended use. LICENESE FEES are in U.S. dollars.

$\triangle$ The LICENSEB is a student or teacher who will use the WORK only for a student project(s) or didactic purposes. LICENSE FBB is waived.

The LICENSEE is a health care professional or health care organization who will use the WORK only in the caro of patients or to evaluate in-house services. LICENSE FEB is $\$ 500$.

$\square$ The LICENSEE is a principal investigator who will use the WORK in not-for-profit research projects. LICENSE FBE is $\$ 500$ per project. Type the title(s) of each project to be covered by this LICENSE in the following space:

The LICENSEE is a pharmaceutical, medical device, biotechnology, disease management or other formprofit entity who will use the WORK to evaluate a product or service that is in development or on the market. LICENSE FEE is $\$ 2,500$ per protocol. Type the title and number of each protocol to be covered by this LICENSE in the following space.

6.2 Enter the total of all applicable LICENSE FEES from Article 6.1. waived

\section{ARTICLE VII-SUBMISSION OF LICENSE \& PAYMENT; NOTIFCATION OF ACCEPTANCE}

7.1 The fully completed LICENSB including signature and LICENSE FEB listed above in Article 6,2 should be sent to the following address. An incomplete or illegible LICBNSE will not be accepted. The UNVERSITY will not send a separate invoice. Please keep a copy of your submission for your records. Payment should bo sent as a check for U.S. dollars made payable to the University of Minnesota. If you do not send tho completed LICENSE and payment together, make sure your payment identifies the LICENSEE and the Minnesota LIVING WITH HEART FAIIUREQ Questionnaire as the reason sending the payment to the UNIVERSITY.

Send completed LICENSE and LICENSE FEE to;

Minnesota LIVING WITH HEART FALUREQ Questionnaire

Office for Technology Commercialization

University of Minnesota

1000 Westgate Drive, Suite 160

St. Paul, MN 55114-8658

7.2 An electronic notification of acceptance will be sent by the UNIVERISTY when both a completed LICENSE and LICENSE FEE are recuived. If this notification is to be sent to an electronic address other than the one listed above in article 1.3, type the person's name and electronic address here:

Name: Samantha Stone

Email address: sstonecfnp@yahoo.com 
LICENSE \# 9/10/2009 11:16 AM

\section{ARTICLE VMI - MRSCELLANEOUS}

8.1 All questions about the LICENSB or WORK should be sent to info@mlbfo.org. The UNIVERSITY is under no obligation to provide support for the WORK.

8.2 This LICENSE contains the entire agreement of the parties conceming this subject matter and supersedes all other previous understandings and statements, written or oral, concerning this matter.

8.3 This LICENSE is binding upon and shall inure to the benefit of the LICENSEE's successors and/or assigns.

8.4 This LICENSE shall be intorpreted and applied in accordance with the laws of the State of Minnesota.

8.5 Headings are for convenience only and are not to be used in interpreting this LICENSE.

8.6 The terms of this LICENSE cannot be orally modified. A modification is not effective unless it is in writing and signed by the LICENSEB and the UNIVERSITY.

IN WITNESS WHEREOF, the LICENSEE agrees to the above terms by the signature below of their duly auchorized ropresentatives.

(LICENSEE) _ $\quad$ _

By:
(authorized signature)

Samantha Stene, MSN, C-ENP

(print name and titie)

Date: 09/10/09

LIVING WITH HEART FAILURB(B) is a registered trademark of the Regents of the University of Minnesota. 


\section{Appendix D}

\section{Letter of Support}

West Virginia Heart and Vascular Institute

4607 MacCorkle Avenue S.W. Suite 300

September 10, 2010

South Charleston, West Virginia 25309-1364

$304-767-7780$

To Whom It May Concern:

The cardiologists at West Virginia Heart and Vascular Institute have agreed to support Samantha Stone, MSN, C-FNP during her doctoral capstone project. As per our agreement, we will allow Miss Stone access to our heart failure patients so she may implement her nurse-led telephone intervention. Miss Stone will be allowed access to our patient data base in order to identify patients with a diagnosis of heart failure, are symptomatic, and have had a hospital admission within six months prior to implementation of the capstone project.

We will also provide Miss Stone with access to any office supplies (free of charge) in order to implement this project. She will also have the opportunity to educate our physicians and office personnel about the project and she may utilize the medical office staff (free of charge during working hours) in order to assist her with providing the intervention, follow-up, any additional scheduling of appointments, and/or necessary testing that may result.

In return, Miss Stone, will treat our patients with respect, dignity, and maintain their confidentiality as per HIPPA law. She also will treat all staff members with respect and dignity. At the completion of the capstone project, she will provide our office with a written report of her findings, therefore; a decision can be made in regard to the need of a practice change.

Lesa Adkins, MSN, RN

Samantha Stone, MSN, C-FNP

Office manger 


\section{Appendix E}

\section{Pre-scripted Telephone Intervention}

Patient ID
Date

Co-morbidities: HTN:____ Diabetes:___ ETOH:____ Smoking:

Hello this is Samantha, we met the other day in Dr._office and we talked about ways to better manage your heart failure. We agreed that we would talk on the phone weekly for six weeks to see how you are doing. If this is a good time, I would like to take about ten minutes to ask you a few questions and answer any questions that you may have. If this is a good time for you, would you mind getting your action plan and your self-care booklet that I gave you?

1) When was the last time you saw your doctor?

2) Have you been in the hospital since we last talked?

3) On a scale of one to five, with one being feeling very poorly and five being feeling very good, how would you rate the way you have been feeling today and over the past week?

Today: $\begin{array}{lllllll}1 & 2 & 3 & 4 & 5\end{array} \quad$ Over the past week: 122345

4) Using the scale how well is your BP controlled?

12345

What is your BP today? unsure

5) I remember you saying that you were diabetic, how well are your blood sugar controlled?

122345

a) Do you see your family doctor regularly for this? Yes/no

b) What was your last $\mathrm{HgA1c}$ ? unsure

6) You also told me that you like to have an alcoholic drink on occasion. What do you like to drink and about how many a day do you have?

Remember that we talked about how when your heart is not pumping very well, it can make you hold onto more fluid? The best way to watch this is by weighing yourself the same time 
everyday? If you gain 2 or more pounds in 24 hours or 4 pounds in a week this could be a sign that your heart failure is getting worse.

1) What was your weight today? \#s

2) Looking at your weight log in your booklet, have you gained any weight this week?

If yes, how much? \#s

If patient did not weigh him/herself. What kept you from weighing yourself today?

Swelling in your legs, feet, hands and belly are another way to tell if your heart is having problems with pumping. Have you been having swelling over the past week? On a scale of 1-5 with one being none and five being severe, how would you rate your swelling?

\section{5}

Too much salt/sodium in your diet can also cause swelling because it makes your body hold onto the fluid instead of getting rid of it. Most patients with HF are asked to limit their salt/sodium intake to 2,000-3,000mg which is the same as 2-3 grams per day.

How much salt/sodium have you been told that you can have per day? $\mathrm{mg} /$ grams/ unsure

How much salt do you have on most days? $\mathrm{mg} /$ grams unsure

Tell me three things that are helping you limit your salt intake.

1)

2)

3)

If unable to identify: I understand that it is hard to adjust to the changes when you have heart failure. Here are some ideas on how to monitor your salt/sodium in your diet.

1) Read labels and look for food/drinks that are less than 140 grams per serving.

2) Don't add salt to your food and a good way to keep you from doing this is by removing the salt shaker from the table all together.

3) Avoid processed foods because most are high in sodium

4) Keep a diary of everything you eat and how much sodium it has per serving. If you are unsure of how much it has write it down anyway and discuss this with your health care provider on your next visit.

Do you think these are some things that you will be able to do? Yes/ no 
Holding onto fluid can also cause you to have shortness of breath. Using the scale of 1-5 again, how has your breathing been today and over the past week?

$$
\text { Today? } 12345 \quad \text { Over the past week? } 1223445
$$

On the 1-5 scale how is your shortness of breath with the following activities?

a. Walking room to room? 122345

b. Walking from inside the house to outside? 12345

c. Walking up stairs? 122345

d. Lying down at night? $1223 \quad 4 \quad 5$

i. How many pillows do you use at night?

ii. Do you have to sleep in a chair at night to keep from getting short of breath? Yes No

e. When you are at rest? $1223 \quad 3 \quad 5$

f. When you get short of breath how do you make it better?

g. Are you still smoking? (if smoker)

h. If so, how much?

I am sure you are on multiple medications but each one is different in the way it helps manage your HF. Lets talk about your medications.

1) What changes have been made to your medications since we first talked?

None/ do not know/

Changes and who made them:

2) Do you take all of your medications every day? yes/ no

3) Do you ever skip or accidentally miss any medications? yes/no

If no to \#2 and/or yes to \#3 document which medications and why

4) How do you keep track of your medications?

5) What do you do when you are running low on your medications if you do not have any refills left at the pharmacy?

Keeping active is another way to keep your heart working better and also make you feel better. What kind of physical activity have you done in the past 3 days?

Great, tell me what helps you to get up and move? 
If none

I understand that being active can be hard at first what do you think is keeping you from exercise?

Here are some tips that may help you get started with improving your activity:

1) Start slowly and gradually increase your activity as you can tolerate

2) Pick an activity you enjoy

3) Find someone to join you in your activities

Some of the other symptoms that people with HF experience are feeling tired, dizziness or lightheadedness, and heart racing or fluttering. Using the 1-5 scale again with 1 being mild and 5 being severe.

1) Are you more tired than usual? 12345

2) Are you having any dizziness or lightheadedness? 122345

3) Are you having any heart racing or fluttering? 122345

Mr./Mrs. thank you for taking the time to talk with me today. Based on what we talked about, where do you think you are on the action plan and what does that mean? (able to identify? Yes/no)

Do you have any questions about your heart failure treatment? No/ Yes (document)

Thank you again and I will call you again on between . Will that work for you? Great, I look forward to talking to you then. In the mean time, remember to take care of your heart by weighing yourself every morning, eating less salt, exercising as your doctor has told you and taking your medications every day. Don't forget to look and see where you are on your action plan every day and call your doctor or 911 when you need to do so. 


\section{Appendix F}

\section{Heart Failure Symptom Awareness and Action Plan Symptom Action}

\begin{tabular}{|c|c|}
\hline $\begin{array}{l}\text { If you have: } \\
\text { - No shortness of breath } \\
\text { - A usual amount of ankle swelling } \\
\text { - No weight gain } \\
\text { - No chest pain } \\
\text { - No change in your usual activity level }\end{array}$ & $\begin{array}{l}\text { Your symptoms are under control. } \\
\text { - Continue taking your medications } \\
\text { as ordered } \\
\text { - Continue to weigh yourself } \\
\text { every day } \\
\text { - Follow a low-salt diet } \\
\text { - Keen all nhvsician annointments }\end{array}$ \\
\hline \multirow[t]{2}{*}{$\begin{array}{l}\text { If you have any of the following: } \\
\text { - Weight gain of } 2 \text { or more pounds } \\
\text { - Increased cough } \\
\text { - Increased swelling } \\
\text { - Increased shortness of breath with activity } \\
\text { - Increased number of pillows needed to sleep }\end{array}$} & $\begin{array}{l}\text { You may need an adjustment of } \\
\text { your medications. } \\
\text { Call your health care contact } \\
\text { for instructions: } \\
\text { Name }\end{array}$ \\
\hline & Number \\
\hline $\begin{array}{l}\text { If you have any of the following: } \\
\text { Shortness of breath at rest } \\
\text { Wheezing or chest tightness at rest } \\
\text { Need to sit in chair to sleep } \\
\text { Weight change of more than } 5 \text { pounds over or } \\
\text { under normal weight } \\
\text { Dizziness, extreme fatigue, or falling }\end{array}$ & $\begin{array}{l}\text { You need to see a doctor now. } \\
\text { Call your doctor today: } \\
\text { Name } \\
\text { Number }\end{array}$ \\
\hline $\begin{array}{l}\text { If you have: } \\
\text { Unrelieved shortness of breath } \\
\text { Unrelieved chest pain } \\
\text { Confusion or fainting }\end{array}$ & $\begin{array}{l}\text { Call 9-1-1 } \\
\text { immediately }\end{array}$ \\
\hline
\end{tabular}


Appendix G

\section{Patient Satisfaction Survey}

On a scale of 1-5 please answer the following questions.

$$
\text { Extremely/ Very/ Somewhat/ Not Very/ Not at all }
$$

How satisfied were you with the information provided to you during each phone call?

$\begin{array}{lllll}5 & 4 & 3 & 2 & 1\end{array}$

How satisfied were you with how you were treated?

5

4

3

21

How satisfied were you with your outcomes?

5 5

Do you feel the telephone call helped you understand more about HF?
Do you feel that you can now manage your symptoms better?
5

5

4

4

3

3

21

Do you know what to do when 5 your symptoms change or worsen?

$\begin{array}{lllll}4 & 3 & 2 & 1\end{array}$

Did you at anytime during this process go to ER? Yes No

$\begin{array}{ll}\text { Was it for heart failure symptoms? } & \text { Yes No }\end{array}$

Were you admitted to the hospital during this process? Yes No 
Appendix H

Staff satisfaction survey

Did this intervention require

yes no

more work from you?

If yes, please explain

If your patient's benefited from

yes no the intervention, would you like to see this as a practice change?

If no, please explain

If you could change something about the project, what would it be?

Please explain

Thank you for your time and participation! 


\section{Appendix I}

\section{Heart Failure Assessment (pre and post intervention)}

Based on the following scale, answer the questions about your heart failure:

\section{$1=$ Never 2 = Almost never $3=$ Some of the time $4=$ Almost always} $5=$ All of the time/always

I keep all my scheduled doctor appointments.

I know when I should call my doctor about my symptoms.

I keep track of how much salt/sodium I have every day.

I weigh myself every day and keep track of my weight gain?

I smoke.

I drink alcohol.

I take all my medications every day.

I exercise on a regular basis.

I watch for swelling of my hands, legs, feet and belly.

My diabetes is under control (if diabetic).

I monitor my blood pressure regularly.

I know what to do when I get short of breath.

I can list my heart failure medications.

I know why I take each medication.

I can list three ways to reduce salt/sodium in my diet.

I feel that I know how to manage my heart failure

I know who and when to call if I have questions or concerns. $\begin{array}{lllll}1 & 2 & 3 & 4 & 5\end{array}$

$\begin{array}{lllll}1 & 2 & 3 & 4 & 5\end{array}$

$\begin{array}{lllll}1 & 2 & 3 & 4 & 5\end{array}$

$\begin{array}{lllll}1 & 2 & 3 & 4 & 5\end{array}$

$\begin{array}{lllll}1 & 2 & 3 & 4 & 5\end{array}$

$\begin{array}{lllll}1 & 2 & 3 & 4 & 5\end{array}$

$\begin{array}{lllll}1 & 2 & 3 & 4 & 5\end{array}$

$\begin{array}{lllll}1 & 2 & 3 & 4 & 5\end{array}$

$\begin{array}{lllll}1 & 2 & 3 & 4 & 5\end{array}$

$\begin{array}{lllll}1 & 2 & 3 & 4 & 5\end{array}$

$\begin{array}{lllll}1 & 2 & 3 & 4 & 5\end{array}$

$\begin{array}{lllll}1 & 2 & 3 & 4 & 5\end{array}$

$\begin{array}{lllll}1 & 2 & 3 & 4 & 5\end{array}$

$\begin{array}{lllll}1 & 2 & 3 & 4 & 5\end{array}$

$\begin{array}{lllll}1 & 2 & 3 & 4 & 5\end{array}$

$\begin{array}{lllll}1 & 2 & 3 & 4 & 5\end{array}$

$\begin{array}{lllll}1 & 2 & 3 & 4 & 5\end{array}$ 


\section{Appendix $\mathbf{J}$}

\section{Demographic Sheet}

Patient ID \#

What is your age?

In what town or city do you live?

Do you live by yourself? Yes/no

Do you eat most of your meals at home? Yes/no

Do you do your own cooking? Yes/no

What is your sex? Male/ female

What is your race? American Indian/ Alaska Native/ Asian/ Black or African American, Native Hawaiian or Other Pacific Islander (NHOPI), White (nonhispanic), multiracial

What is your level of education? 122345667899101112

College graduate/Masters degree or higher?

Do you have difficulty reading? Yes/no

Do you have difficulty understanding written information? Yes/no

Do you have any hearing problems? Yes/no

Do you have a home telephone? Yes/no

Do you have a cell phone that gets good reception at your home? Yes/no

Would you like to know more about your heart failure? Yes/no

When the office RN called you about your appointment, you said that you would like to participate in a weekly telephone intervention in order to better manage your heart failure, are you still willing to do so? Yes/no

Consent obtained? Yes/ no 